\title{
Sustainability of participation in collective pension schemes: An option pricing approach
}

Citation for published version (APA):

Chen, D. H. J., Beetsma, R. M. W. J., Broeders, D. W. G. A., \& Pelsser, A. A. J. (2017). Sustainability of participation in collective pension schemes: An option pricing approach. Insurance: Mathematics and Economics, 74, 182-196. https://doi.org/10.1016/j.insmatheco.2017.03.007

Document status and date:

Published: 01/05/2017

DOI:

10.1016/j.insmatheco.2017.03.007

Document Version:

Publisher's PDF, also known as Version of record

Document license:

Taverne

\section{Please check the document version of this publication:}

- A submitted manuscript is the version of the article upon submission and before peer-review. There can be important differences between the submitted version and the official published version of record.

People interested in the research are advised to contact the author for the final version of the publication, or visit the DOI to the publisher's website.

- The final author version and the galley proof are versions of the publication after peer review.

- The final published version features the final layout of the paper including the volume, issue and page numbers.

Link to publication

\footnotetext{
General rights rights.

- You may freely distribute the URL identifying the publication in the public portal. please follow below link for the End User Agreement:

www.umlib.nl/taverne-license

Take down policy

If you believe that this document breaches copyright please contact us at:

repository@maastrichtuniversity.nl

providing details and we will investigate your claim.
}

Copyright and moral rights for the publications made accessible in the public portal are retained by the authors and/or other copyright owners and it is a condition of accessing publications that users recognise and abide by the legal requirements associated with these

- Users may download and print one copy of any publication from the public portal for the purpose of private study or research.

- You may not further distribute the material or use it for any profit-making activity or commercial gain

If the publication is distributed under the terms of Article $25 \mathrm{fa}$ of the Dutch Copyright Act, indicated by the "Taverne" license above, 


\title{
Sustainability of participation in collective pension schemes: An option pricing approach
}

\author{
Damiaan H.J. Chen ${ }^{\mathrm{a}}$, Roel M.W.J. Beetsma ${ }^{\mathrm{b}, *}$, Dirk W.G.A. Broeders ${ }^{\mathrm{c}}$, Antoon A.J. Pelsser ${ }^{\mathrm{d}}$ \\ ${ }^{a}$ MInt/Amsterdam School of Economics, University of Amsterdam, MN, Tinbergen Institute, DNB, P.O. Box 15867, 1001 NJ Amsterdam, The Netherlands \\ ${ }^{\mathrm{b}}$ MN Chair in Pension Economics, University of Amsterdam, European Fiscal Board, CEPR, CESifo, Netspar, Tinbergen Institute, The Netherlands \\ ${ }^{\mathrm{c}}$ DNB, Maastricht University, The Netherlands \\ d Maastricht University, Netspar, Kleynen Consultants, The Netherlands
}

\section{A R T I C L E I N F O}

\section{Article history:}

Received September 2015

Received in revised form

March 2017

Accepted 24 March 2017

Available online 13 April 2017

\section{JEL classification:}

C61

G23

J32

Keywords:

Defined-benefit

Collective defined-contribution and hybrid

pension funds

Participation decision

Contribution

Option

Least Squares Monte Carlo method

Explicit finite difference method

Sustainability

\begin{abstract}
A B S T R A C T
This paper contributes to the discussion about mandatory participation in collective funded pension schemes. It explores under what circumstances individual participants exercise the option to exit such a scheme if participation is voluntary. We begin by showing how the willingness to participate increases if the period over which the option is valid becomes longer. Then, we demonstrate how the pension fund's set of policy instruments can be deployed to minimize the likelihood that any cohort exits the pension scheme. The instruments consist of contribution and indexation policies. Recovery of the funding ratio, i.e. the ratio of assets over liabilities, to its regulatory target level may be based on uniform contributions or age-dependent contributions. Specifically, while the value of the exit option deters younger workers from exiting the pension fund, a uniform contribution policy encourages older workers to stay in the pension scheme.
\end{abstract}

(C) 2017 Elsevier B.V. All rights reserved.

\section{Introduction}

This paper explores the sustainability of a collective funded pension scheme when participation in such a scheme is voluntary. It also explores how regulatory policies can be designed so as to induce pension fund participants not to exit the scheme, which would be an alternative to making participation mandatory if participation is deemed desirable.

\footnotetext{
is We thank an anonymous referee, Hans Schumacher, Arjen Siegmann, Ward Romp, Michel Vellekoop, Ed Westerhout, seminar participants at the Dutch central bank (DNB) and participants at the Netspar International Pension Workshop for many helpful comments and suggestions. The views expressed in this paper are the authors' own views and do not necessarily coincide with those of any of the institutions they are affiliated with.

* Corresponding author.

E-mail addresses: D.H.J.Chen@UvA.nl (D.H.J. Chen),r.m.w.j.beetsma@uva.nl (R.M.W.J. Beetsma).
}

Participation in collective pension schemes can be either mandatory or voluntary. Many countries feature pension arrangements with mandatory participation. Examples are the sub-national civil servants' pension schemes in the US and most occupational pension arrangements in the Netherlands and Denmark. The funded pension schemes in Australia, Chile, Iceland, Norway, Sweden and Switzerland, among others, are mandatory for all employees or even all wage earners (OECD, 2013). Mandatory participation in collective pension schemes may be beneficial for several reasons. First, and most important, individuals are protected against the consequences of their own myopia, which deters them from saving enough for their retirement. Second, it allows for intergenerational risk-sharing. This is ex-ante welfare enhancing as it allows shocks to be distributed over a large group of subsequent cohorts. Consequently, shocks have less impact on the disposable income of participants in a collective pension scheme compared to participants in individual schemes (Gordon and Varian, 1988; Shiller, 1999; Ball and Mankiw, 2007; Gollier, 2008; Cui et al., 2011; 
Chen et al., 2016). Finally, a collective scheme may operate at lower costs, because of economies of scale, while the obligation to participate avoids expenditures on marketing activities.

Despite these advantages, mandatory participation in collective pension schemes is under pressure. Increasing labour market mobility and self employment require more flexible pension arrangements (Chen and Beetsma, 2015). Furthermore, the potential benefit of intergenerational risk sharing may become smaller due to population ageing. Also the quest for more individual choice has increased. We analyse one aspect of more individual choice by allowing continued participation of the collective pension scheme to be voluntary. The question is what this additional choice flexibility implies for the sustainability of the collective scheme and, thereby, for the possibilities to continue to reap the benefits from participation. In the case of large collective schemes sustainability may also be systemically important, because a run on the assets of a large pension fund may have profound consequences for the financial markets in which it has invested.

This paper applies option pricing techniques to analyse the decision to continue to participate in or to exit a collective funded pension scheme. We also investigate how a pension fund can deploy its policy instruments to reduce the likelihood that a cohort wants to leave the pension fund. Hence, our analysis explores leads for meeting the quest for more individual freedom of choice (Bovenberg et al., 2007; Beetsma et al., 2012; Beetsma and Romp, 2013), while maintaining the sustainability of pension schemes. We analyse a participant's decision to exit the collective pension scheme under the assumption that all the other participants decide to stay in the fund. Hence, we assume that participants are myopic in their beliefs about how other participants may react. Like the assumption of full rationality, under which each participant takes account of the optimal decisions of all the other current and future participants, and what consequences these have for the financial situation of the pension fund, the assumption of myopia is not meant to fully capture how the real world operates. However, the average pension fund participant certainly features some degree of myopia, simply because it is too difficult or time consuming to see through the optimal decisions of all the other participants, and, hence, our assumption of myopia may serve as a useful starting point for more refined assumptions about the participants' beliefs.

We consider different degrees of flexibility to exit, ranging from a "European" option with a single pre-specified exit age to an "American" option that allows for the possibility to exit at any moment until the option expires. An example of the first type is when (only) at the moment of retirement the participant can choose between taking out his accumulated balance or receiving an annuity payment until death. This is the case for Australia, Chile, Denmark, Sweden and Switzerland. ${ }^{1}$ By contrast, in the UK participants have the option to withdraw their entire balance at any moment after the age of 55, while in the US this option exists during the entire working career. An intermediate case is the "Bermudan option", which allows for a finite number of exercise dates. An example concerns the recent introduction in the UK of the obligation of employers to automatically enrol employees every three years into an occupational pension scheme. Participants can withdraw their contributions within a month after enrolment. Thereafter, contributions are locked in the pension scheme until the age of 55. Depending on the pension scheme one might be able to reduce or increase the level of contributions. In particular, the non-profit "NEST" pension scheme, which was set up as part of the government's workplace pension reforms, allows for a

\footnotetext{
1 In Chile, the latter possibility only exists if the annuity exceeds some mandatory minimum. In Sweden, the participant may choose between an annuity until death or an annuity with a fixed maturity of at least five years.
}

"contribution holiday". The participant can keep his retirement pot and start contributing again at a later date.

We set up a model with multiple overlapping generations, in which participants have the option to stay in their pension fund or to once-and-for-all exit it. Exiting the fund may be optimal when the funding ratio, i.e. the value of the fund's assets over its liabilities, is low. By exiting the participant does not share in the future recovery burden. Investment risks affect the financial position of the pension fund, which can deploy two instruments, the contribution and the indexation rate, to restore its financial position. This recovery is required by regulation in our model and can be spread out over a shorter or longer period. The types of pension contracts we consider range from collective defined-benefit (DB), in which all the adjustments take place through the contributions, to a collective defined-contribution (CDC) scheme, in which all adjustments occur through indexation. We also analyse hybrid contracts, with adjustments along both dimensions. In all contract specifications the accrual and indexation rates are uniform for all participants. The considered contribution policies, however, range from a uniform contribution policy, which is common in many collective pension arrangements throughout the world, to one in which the contribution is increasing with age. We also consider a compromise between these two contribution policies. To obtain our numerical results, we apply the explicit finite difference method in the case of a DB scheme and the Least Squares Monte Carlo (LSMC) approach, as proposed by Longstaff and Schwartz (2001), in the case of a CDC or hybrid scheme. By now, several other studies have applied the LSMC approach to pensions and life insurance products, e.g. Pelsser et al. (2007), Bernard and Lemieux (2008), Cathcart and Morrison (2009) and Boyer and Stentoft (2013).

Our key findings are the following. Ceteris paribus, young workers are more inclined to continue participation than older workers, since for the young the period over which the exit option can be exercised is longer. In combination with the uniform accrual rate, a uniform contribution is relatively beneficial to the elderly workers, because they are implicitly subsidized by the young cohorts: the newly accrued pension entitlements associated with an additional year of working are more valuable for older than for younger working cohorts, because the ensuing benefits of the older workers are discounted over a shorter period. For different settings of the policy instruments we explore the sustainability of the pension scheme in terms of the participants' willingness not to exit the scheme. In particular, if recovery relies more on the indexation policy, older workers are more likely to exit. In that case, a uniform contribution policy is conducive to keeping all the cohorts in the fund: young workers are reluctant to exit because the recovery relies relatively heavily on participants with large pension entitlements, i.e. the elderly workers, while the latter benefit from the subsidy implicit in the uniform contribution policy. This "payas-you-go effect" is present in many collective funded public sector pension plans, such as those in Australia, Canada, Germany, the Netherlands, Norway, Switzerland, the UK and the sub-national civil servants' plans in the US (Ponds et al., 2011). Moreover, we find that a reduction in investment risk enhances the sustainability of the pension scheme. Only when investment risk is low, is a longer smoothing period conducive to sustainability.

The existing cohorts effectively pay for the entry cohort's exit option. The option value typically varies between one to three times the annual wage. Under the DB pension scheme young cohorts are most likely to exit. Hence, under policy parameter settings for which the sustainability of the DB pension scheme is high (i.e., all working cohorts are more likely to continue participating) the option value to entry cohorts is low, as they are unlikely to exercise their option. By contrast, for the hybrid and CDC pension schemes the exit option is typically more valuable under policy parameter settings that are conducive to the sustainability of the pension arrangement. 
Closest to the current paper is Chen (2015). This paper extends (Chen, 2015) into a number of directions. In contrast to Chen (2015) we consider hybrid pension schemes and we introduce the indexation rate as an additional instrument to restore the pension fund's financial position. In addition, we allow for the contribution policy to be age-dependent. This way we can explore what policy instrument settings are conducive to all cohorts continuing their participation in the pension fund. This paper differs from other papers studying the decision to participate in a collective pension fund by applying an option pricing approach based on riskneutral valuation by assuming complete markets, rather than a utility-based framework. Siegmann (2011) analyses funding ratio thresholds at which an individual would voluntarily participate in a DB pension fund. Molenaar et al. (2011) analyse whether a low funding ratio creates incentives for participants to exit a pension plan. In line with our results, they find that both young and old working cohorts are likely to exit the pension fund. The exit incentive of the young is driven by the pay-as-you-go effect from the uniform contribution policy, by which their contribution is typically higher than what is actually fair, while the exit incentive of the old is driven by the fact that reductions in indexation affect them relatively severely, because they have a relatively large stock of pension entitlements. Other articles studying participation in collective pension funds and discontinuity risk are van Hemert (2005), Van Bommel (2007), Beetsma et al. (2012), Beetsma and Romp (2013) and Westerhout (2011). Except for applying a utilitybased approach, these papers cast their analysis in a context with two overlapping generations, while we allow for a more realistic setting with a continuum of overlapping generations and a potential continuum of exercise moments. The setup with multiple overlapping generations enables us to analyse different contribution policies for the working cohorts.

As this paper deals with the sustainability of funded pension arrangements, it also relates to the literature on the actuarial fairness of pension schemes and the stability of their funding situation. Several contributions argue that new cohorts are willing to join a pension scheme only if it would offer a better deal than what would be obtained under actuarial fairness. Kleinow and Schumacher (2016) show that maintaining actuarial fairness is not straightforward when risk-sharing is implemented through conditional indexation. They compute a recursive formula in the context of a model with two overlapping generations, such that contributions are actuarially fair for entry generations. If contributions at entry exceed their actuarially fair level, then a new cohort would not join the scheme. We focus on a situation with multiple overlapping generations, which enables us to study the possibility to exit the pension fund. Hassler and Lindbeck (1997) explore pension arrangements that feature both actuarial fairness and a balanced budget. Actuarial fairness imposes restrictions on the relation between retirement benefits and contributions, which affects the budget balance. They show that in a pay-as-you-go pension system with fixed contributions intergenerational risk sharing can only be achieved if the participants have no incentive to dismantle the system during their working period. The latter is the case when the system is actuarially fair. The resulting system is a notional DC pension scheme, on which the current Swedish public pension pillar is based. However, our paper considers funded pension schemes. Dufresne (1989) does not investigate the sustainability of pension schemes per se, but to what extent fluctuations in contributions and funding ratios can be reduced. By contrast, we explore a fund's sustainability directly by focusing on the likelihood that its members continue to participate. Chen and Romp (2016) propose a method to model the behaviour of funded pension schemes by distributing the recovery required by regulation over the policy instruments in such a way that the pension system is globally stable. This feature holds regardless of the extent of risk-sharing and the type of financing $(D B, D C$ or hybrid). We apply this method to ensure non-exploding simulation paths, while we focus on improving sustainability by stimulating participation.

The remainder of this paper is structured as follows. Section 2 presents the model, while Section 3 presents the benchmark parameter settings. As a stepping stone for the ensuing analysis, Section 4 explores the exit option under a DB pension scheme when there is a fixed exercise date, while Section 5 turns to the American exit option and allows for indexation as an additional instrument. Section 6 explores how sustainability can be enhanced by deploying a uniform contribution policy to stimulate participation. Finally, in Section 7 we conclude the main text of this paper. Technical details are found in Appendix A, which will be made available via our homepages.

\section{The model}

This section presents the model. Section 2.1 describes the underlying economy and the individuals inhabiting the economy. Section 2.2 discusses the valuation of random cash-flows, while Section 2.3 explains the various pension schemes.

\subsection{The economy and its agents}

We assume that the only source of risk is investment return risk. Under the actual probability measure $\mathbb{P}$ the value $P_{t}$ of the pension fund's investment portfolio follows a geometric Brownian motion

$d P_{t}=\mu P_{t} d t+\sigma P_{t} d W_{t}^{\mathbb{P}}$,

where the drift equals the expected return on the pension fund's investment portfolio $\mu, \sigma$ is the volatility of the portfolio return and $d W_{t}^{\mathbb{P}}$ is a Brownian motion without drift. We also assume that there is a money market account with a constant return $r$, of which the value evolves as

$d M_{t}=r M_{t} d t$.

We use this asset as the numéraire security. Then, under the riskneutral measure $\mathbb{Q}$ the process of the value of the investment portfolio can be written as

$d P_{t}=r P_{t} d t+\sigma P_{t} d W_{t}^{\mathbb{Q}}$.

The Brownian motions under $\mathbb{P}$ and $\mathbb{Q}$ are related by $d W_{t}^{\mathbb{Q}}=d W_{t}^{\mathbb{P}}+$ $\lambda d t$, where $\lambda=(\mu-r) / \sigma$ is the Sharpe-ratio. All remaining processes in the model are specified under the risk-neutral measure $\mathbb{Q}$.

One unit of time in the model corresponds to one year. An individual works from the age $t_{0}=0$ at which he enters the labour force until his retirement age $t_{R}$, while he is retired from age $t_{R}$ until the age at which he dies, $t_{D}$. The parameters $t_{0}, t_{R}$ and $t_{D}$ are all constant. Moreover, the size of the new cohort entering the workforce is equal to the size of the cohort that passes away. Hence, we abstract from demographic risks. For simplicity, we normalize the number of individuals born within a period of one year to unity. We also abstract from unemployment risk and inflation risk. In fact, we assume that the inflation rate is zero. ${ }^{2}$ The cohort entering the labour market at time $t=s$ is referred to as "cohort $s$ ". Furthermore, we assume that the wage profile is constant over an individual's working life. We normalize the annual wage rate to unity. Hence,

$w_{s, t}= \begin{cases}1, & \text { for } t-s \in\left[0, t_{R}\right], \\ 0, & \text { otherwise }\end{cases}$

where $w_{s, t}$ is the wage of a participant aged $v=t-s$. At date $t$ cohort $s$ contributes a fraction $c_{s, t}$ of its wage to the pension fund.

\footnotetext{
2 Allowing for non-zero inflation would complicate the algebra without affecting the main results.
} 


\subsection{Valuation method}

Key to the analysis will be the participant's option to exit a collective pension fund. At time $t$, the price of any security or contract with random pay-off $X_{u}$ at $u \geq t$ is given by $\Pi_{t}\left(X_{u}\right)$. According to the Fundamental Theorem of Asset Pricing, we can price securities in a complete market as the conditional expectation under the riskneutral measure $\mathbb{Q}$ (Delbaen and Schachermayer, 1994). Hence, we obtain

$\Pi_{t}\left(X_{u}\right)=\exp [-r(u-t)] E_{t}^{\mathbb{Q}}\left(X_{u}\right)$,

where $E_{t}^{\mathbb{Q}}$ is the expectation under the risk-neutral measure $\mathbb{Q}$, conditional on the information available at time $t$.

\subsection{The pension schemes}

In this subsection we define the various possible pension schemes. All pension schemes are funded. We distinguish between an individual DC pension scheme and collective pension schemes. Among the collective schemes we define a continuum of schemes ranging from $\mathrm{DB}$ to $\mathrm{CDC}$. We end this subsection with a description of the option to exit the collective scheme and switch to the individual scheme. In fact, in the current set-up it is irrelevant for the valuation of the exit option whether the individual switches to an individual DC pension scheme or simply saves for himself outside any formal arrangement. We cast the discussion in terms of an individual DC pension scheme, because in practice it is often seen as an alternative to saving for retirement in a collective pension scheme.

\subsubsection{The individual defined contribution scheme}

Under the individual DC pension scheme a participant accumulates assets by paying contributions and earning investment returns. At retirement the accumulated assets are used to buy an annuity. The pension assets of cohort $s$ at time $t$ are

$A_{s, t}^{D C}=\int_{s}^{t} c^{D C} \frac{P_{t}}{P_{u}} d u, \quad$ for $t-s \in\left[0, t_{R}\right]$,

where $c^{D C}$ is the constant contribution. Assets at retirement, $A_{s, s+t_{R}}^{D C}$, are used to buy an annuity that yields a constant benefit $B^{D C}$ until death. This benefit is easily calculated as (see Appendix A.1)

$B^{D C}=r A_{s, s+t_{R}}^{D C} /\left\{1-\exp \left[-r\left(t_{D}-t_{R}\right)\right]\right\}$.

The individual DC pension scheme is actuarially fair by construction. By applying the valuation method, we simply obtain

$\Pi_{t}\left(A_{s, t}^{D C}\right)=A_{s, t}^{D C}, \quad s \leq t$.

\subsubsection{The collective pension scheme}

The collective schemes are more complex. We run through several steps in this section to model them. First, we define the participation setting. Second, we present the asset dynamics and the valuation of the liabilities. Third, we turn to the various policy instruments available to the scheme. Fourth, we address the regulation of the scheme and determine the equilibrium values of the funding ratio and liabilities. We refer to an equilibrium as a situation in which there is full participation, the funding ratio remains constant in expectation at its target level and the indexation rate has been constant at its target level over the pension fund's history. ${ }^{3}$ Fifth, we classify the various collective

\footnotetext{
3 The equilibrium will almost surely not be achieved at some given point in time in the future. However, variables, such as the funding ratio, may achieve their equilibrium value without the entire system being in equilibrium.
}

pension schemes. We finish this subsection with a description of the recovery contribution policy.

Participation setting Denote $I_{t}$ as the set of participating cohorts in the collective pension scheme at time $t$. These cohorts must have entered the labour market at time $s \in\left[t-t_{D}, t\right]$. Under "full participation" all cohorts currently alive participate in the pension fund. Hence, in this case, $I_{t}=\left\{s: t-s \in\left[0, t_{D}\right]\right\}, \forall t$, where $t-s$ is the age of cohort $s$. Under full participation the set of working cohorts in the collective pension scheme at time $t$ is

$I_{t}^{w}=\left\{s: t-s \in\left[0, t_{R}\right]\right\} \cap I_{t}$,

while the set of retired cohorts participating at time $t$ is

$I_{t}^{r}=\left\{s: t-s \in\left[t_{R}, t_{D}\right]\right\} \cap I_{t}$.

Asset dynamics. The value of the pension fund's assets $A_{t}$ evolves as

$d A_{t}=\frac{d P_{t}}{P_{t}} A_{t}+\left(C_{t}-B_{t}^{T O T}\right) d t$

Hence, the pension fund's assets grow according to the stochastic portfolio return $\left(d P_{t} / P_{t}\right)$ as defined in Eq. (2), plus the total volume of contributions $\left(C_{t}\right)$, minus the total volume of benefit payments $\left(B_{t}^{T O T}\right)$.

Valuation of the liabilities. The price of the pension entitlements of cohort $s$ at time $t$ is

$\Pi_{t}\left(B_{s, t}\right)=R_{t-s} B_{s, t}$,

where $R_{t-s}$ is the annuity factor for the pension entitlements and $B_{s, t}$ are the accumulated pension entitlements of cohort $s$ at time $t$. That is, if $t$ is the current period, $B_{s, t}$ is the level of the benefit of cohort $s$ projected as of now if the cohort is retired and as of retirement date if the cohort is not yet retired and no account is taken of further accrual, because the associated contributions have not yet taken place. To derive the annuity factor we distinguish between the pre- and the post-retirement period. For a cohort of age $v=t-s$ the annuity factor is given by

$$
\begin{aligned}
R_{v} & = \begin{cases}\exp \left[-r\left(t_{R}-v\right)\right] & \text { for } v \in\left[0, t_{R}\right], \\
\int_{t_{R}}^{t_{D}} \exp \left[-r\left(u-t_{R}\right)\right] d u, & \text { for } v \in\left(t_{R}, t_{D}\right), \\
\int_{v}^{t_{D}} \exp [-r(u-v)] d u, & \\
= & \frac{\exp (r v)}{r}\left\{\exp \left(\left[-r \max \left(t_{R}, v\right)\right]\right)-\exp \left(-r t_{D}\right)\right\} .\end{cases}
\end{aligned}
$$

The pension fund's liabilities equal the discounted pension entitlements integrated over all the participating cohorts ${ }^{4}$

$$
L_{t}=\int_{I_{t}} R_{t-s} B_{s, t} d s .
$$

The policy instruments. The collective pension scheme has two policy instruments available to respond to financial shocks: the rate at which accrued pension entitlements are indexed and the contribution. We refer to the policies associated with these

\footnotetext{
4 Note that the valuation of the liabilities does not include the value of a potential exit option. The liabilities are calculated as if none of the current participants will exit the pension fund. This is how liabilities are often calculated in practice. Including the participation decision in the valuation of the liabilities would complicate the model so substantially that it is beyond the scope of the current paper, while it would not provide a more realistic description of the calculation of the liabilities as an input for the funding ratio, which forms the basis for the pension fund's instrument settings.
} 
instruments as the "indexation policy" and the "contribution policy".

The indexation policy is specified as follows. The pension entitlements of cohort $s$ at time $t$ evolve as

$d B_{s, t}=\left[\psi w_{s, t}+\left(\gamma_{t}-1\right) B_{s, t}\right] d t, \quad$ for $t-s \in\left[0, t_{D}\right)$,

where $\psi$ is the accrual rate as a constant fraction of the wage rate and $\gamma_{t}$ is the (gross) indexation rate to the existing stock of entitlements. All the participants in the pension arrangement receive the same indexation. Note that the wage rate, and, hence, also accrual, are zero during retirement, since $w_{s, t}=0$ for $t-s \notin$ $\left[0, t_{R}\right]$. Because entitlements are zero at the moment of entry into the labour force, we have $B_{s, s}=0$. The indexation rate allows the pension fund to respond to its funding ratio by marking up or marking down the existing stock of pension entitlements. Because inflation is zero, we calibrate the indexation policy such that the indexation rate is $\gamma_{t}=\bar{\gamma}=1$ in equilibrium. Hence, in that case, benefits of the retirees grow at a rate of zero. Integrating over all retired cohorts, the pension fund's period- $t$ aggregate benefit payments are

$B_{t}^{T O T}=\int_{I_{t}^{r}} B_{s, t} d s$

The second policy instrument concerns the contribution. The contribution $c_{s, t}$ by an individual from cohort $s$ at time $t$ is the sum of a basic contribution $\left(\bar{c}_{t-s}\right)$ and a recovery contribution $\left(\pi_{s, t}\right)$. Aggregate contributions over all working cohorts are given by

$C_{t}=\int_{I_{t}^{w}} c_{s, t} d s=\int_{I_{t}^{w}} \bar{c}_{t-s} d s+\bar{\pi}_{t}$,

$\pi_{t}=\int_{I_{t}^{w}} \pi_{s, t} d s$,

where the basic contribution is

$\bar{c}_{t-s}=\psi w_{s, t} R_{t-s}= \begin{cases}\psi R_{t-s}, & \text { for } t-s \in\left[0, t_{R}\right], \\ 0, & \text { otherwise. }\end{cases}$

This basic contribution $\bar{c}_{t-s}$ equals the net present value of the corresponding pension accrual in the absence of shocks and when the option to exit the collective pension scheme is ignored. The recovery contribution $\pi_{s, t}$ can be positive or negative, depending on the pension fund's financial position.

Regulation. The collective pension schemes are regulated, for example by a supervisor appointed by the government. The key input is the funding ratio

$F_{t}=A_{t} / L_{t}$.

The regulator requires pension funds to target in the long-run an average funding ratio of $\bar{F}$, the "target funding ratio". When the actual funding ratio $F_{t}$ deviates from the target funding ratio, the regulator requires the pension fund to close the gap between the two at a sufficiently high speed according to the following schedule:

$d E_{t}^{\mathbb{P}}\left(F_{t}\right)=(\log \alpha)\left(F_{t}-\bar{F}\right) d t, \quad 0<\alpha<1$,

where $\alpha$ denotes a regulatory smoothing parameter. We have that $\log \alpha<0$, as $\alpha \in(0,1)$. Hence, regulation implies that the funding ratio is mean reverting in expectation. The smoothing parameter allows for a gradual adjustment to financial shocks. The smoothing parameter is crucial in determining the distribution of the adjustment burden across the cohorts. For example, when the parameter is high, recovery from a low funding ratio will be smoothed out over a long horizon, implying that the oldest cohorts will have died before most of the adjustment has taken place. In the sequel, we will refer to $F_{t}-\bar{F}$ as the "funding gap". From Eq. (3) follows immediately that

$E_{t}^{\mathbb{P}}\left(F_{t+u}-\bar{F}\right)=\alpha^{u}\left(F_{t}-\bar{F}\right)$.

This means that after $u$ years the fraction $\alpha^{u}$ of the funding gap is still left in expectation, while the fraction $1-\alpha^{u}$ has been restored. Because the long-run average funding ratio is $\bar{F}$, this is the equilibrium value of the funding ratio. Since we abstract from inflation, we assume the regulator targets a funding ratio of $100 \%$, i.e. $\bar{F}=1$. Then, under full participation and the assumptions of a long-run average funding ratio of one and an equilibrium indexation rate of one, Appendix A.2 shows that the equilibrium values of aggregate recovery contributions and liabilities are given by, respectively

$$
\begin{aligned}
& \bar{\pi}=(r-\mu) \bar{L} \\
& \bar{L}=\frac{\psi}{r}\left[t_{R}\left(t_{D}-t_{R}\right)-\bar{R}\right],
\end{aligned}
$$

where for ease of notation we define

$\bar{R}=\int_{t-t_{R}}^{t} R_{t-s} d s=\frac{\left[\exp \left(-r t_{R}\right)-\exp \left(-r t_{D}\right)\right]\left[\exp \left(r t_{R}\right)-1\right]}{r^{2}}$.

Hence, with a strictly positive pension fund risk premium, i.e. $\mu-$ $r>0$, the aggregate recovery contributions are negative when all variables are at their equilibrium levels. Recall that an equilibrium in period $t$ implies for the funding ratio that $E_{t}^{\mathbb{P}}\left(F_{t+u}\right)=\bar{F}, \forall u \geq 0$.

Classification of collective pension arrangements. The pension fund thus uses its two policy instruments, the recovery contribution $\left(\pi_{s, t}\right)$ and the indexation rate $\left(\gamma_{t}\right)$, to manage the funding gap. Variations in these instruments have different impacts on the pension fund's various participating cohorts. The recovery contribution is paid by the active members (the workers), while the indexation rate affects both the active and retired participants. Its impact differs by the relative amount of accumulated pension entitlements.

Because the regulator requires the pension fund to control the funding ratio gap according to Eq. (3), this imposes a restriction on the policy instruments $\bar{\pi}_{t}$ and $\gamma_{t}$ used by the pension fund. To formulate this constraint, we first define the "total correction" $\Omega_{t}$ as

$\Omega_{t} \equiv\left(F_{t}-1\right)\left[(\log \alpha) L_{t}+\psi \bar{R}-B_{t}^{T O T}\right]-(\mu-r)\left(A_{t}-\bar{L}\right)$.

This total correction captures the part implied by regulatory policy that in period $t$ has to be covered by additional contributions and deviations of the indexation rate from unity. We show in Appendix A.2 that we can rewrite

$\Omega_{t}=\left(1-\gamma_{t}\right) A_{t}+\left(\pi_{t}-\bar{\pi}\right)$.

We now define the parameter $\omega$ as the fraction of the total correction $\Omega_{t}$ that is to be achieved through adjusting indexation. By definition, the remainder $(1-\omega)$ of the total correction is to be achieved through contribution adjustments. A pension fund board that seeks to control the funding ratio gap according to Eq. (3) sets its policy instruments such that

$$
\begin{aligned}
\left(1-\gamma_{t}\right) A_{t} & =\omega \Omega_{t}, \\
\left(\pi_{t}-\bar{\pi}\right) & =(1-\omega) \Omega_{t} .
\end{aligned}
$$

This specification of the policy instruments allows us to classify collective pension schemes according to their value for $\omega$. At the one end, if $\omega=0$, the scheme is of the collective DB type. There is no uncertainty about the benefits, as $\gamma_{t}=1, \forall t$. Instead, all of the investment risk is absorbed through changes in current and future contributions. At the other end, if $\omega=1$, the pension scheme is of the CDC type. None of the correction takes place 
Table 1

Classification of specific collective pension schemes.

\begin{tabular}{llll}
\hline Hybridity parameter: & $\omega=0$ & $\omega \in(0,1)$ & $\omega=1$ \\
Pension scheme: & DB & Hybrid & Collective DC \\
\hline
\end{tabular}

through contributions. In this case, all of the investment risk is allocated directly to the active participants through an adjustment of their entitlements and to the retirees through an adjustment of their benefits. For $0<\omega<1$, we have a so-called "hybrid" pension scheme. A hybrid pension scheme uses both benefit and contribution adjustments to allocate investment risk to the participants. Table 1 summarizes these cases. In the sequel we refer to $\omega$ as the "hybridity parameter".

The assumed specification of the policy instruments features a constant hybridity parameter. However, there are many possible specifications in addition to the one proposed here. For example, the hybridity parameter could be made dependent on the funding ratio.

The recovery contribution policy. We assume that the recovery contribution is independent of age. Appendix A.4 shows that the time $t$ recovery contribution paid by a participant of age $t-s \in$ $\left[0, t_{R}\right]$ is

$\pi_{s, t}=\frac{(1-\omega) \Omega_{t}+\bar{\pi}}{\int_{I_{t}^{w}} 1 d s}$.

Since $\partial c_{t-v, t} / \partial \Omega_{t} \geq 0$, the age-dependent recovery contribution is increasing in the correction factor $\Omega_{t}$.

\subsubsection{The option to exit the collective scheme}

Above we have described the individual DC pension scheme and a continuum of collective schemes, ranging from DB to CDC. Under the DB pension scheme financial shocks are fully absorbed by adjusting contributions. Under the CDC pension scheme shocks are fully absorbed by adjusting indexation. As a final step to complete our model, we introduce the option for a participant to exit the collective scheme. Doing so means that he switches from the collective scheme to the individual DC pension scheme. This switch is assumed to be irreversible.

We assume that by default an individual enters the labour market as a member of the collective pension scheme. An individual entering at time $s$ will receive pension benefits with value $\int_{s+t_{R}}^{s+t_{D}} B_{s, t} e^{-r t} d t$, but may also choose to exit before retirement, i.e. at age $v<t_{R}$. Hence, the individual holds an option to exit the collective scheme that matures at the retirement date. ${ }^{5}$ If the option is exercised at some age $v \in\left[0, t_{R}\right]$ during the accrual phase, then the accumulated pension rights $B_{t-v, t}$ are converted into personal assets $A_{t-v, t}^{D C}$, which is the early-exercise payoff received by the individual according to

$A_{t-v, t}^{D C}=\min \left(1, F_{t}\right) \Pi_{t}\left(B_{t-v, t}\right)$.

This rule implies that in case of underfunding, $F_{t}<1$, the amount of personal assets he receives is the present value of his projected benefits reduced by a factor equal to the fraction by which the current funding ratio falls below $100 \%$. This way, the funding ratio remains the same when an agent exits. In the case of overfunding, the individual simply receives the present value of his projected benefits. Without this last rule participants would at retirement take out part of the pension fund's positive buffer and switch fully to saving and investing via an individual account. Effectively, in the

\footnotetext{
5 Madrian and Shea (2001) find that only a small fraction of participants decide to opt out if they enter by default, but have the option to quit.
}

case of overfunding a pension fund's participant suffers a penalty if he leaves the fund. This penalty resembles a written put option on the fund's assets.

After exiting the fund at age $v$, the individual transfers his personal assets into an individual DC account of which the value during the remaining part of his working life evolves as

$A_{t-v, \tau}^{D C}=A_{t-v, t}^{D C} \frac{P_{\tau}}{P_{t}}+\int_{t}^{\tau} c^{D C} \frac{P_{\tau}}{P_{u}} d u, \quad$ for $\tau-t+v \in\left[v, t_{R}\right]$.

\section{Parametrization and simulation setup}

Now we turn to the numerical part of the analysis. Table 2 reports the choice of the benchmark parameter values. ${ }^{6}$ We assume that, in equilibrium, the indexation rate is $\bar{\gamma}=1$ and the funding ratio is $\bar{F}=1$. Also, we assume that the pension scheme always operates under full participation. Hence, we set $I_{t}=\left\{s: t-s \in\left[0, t_{D}\right]\right\}, \forall t$. This means that all cohorts who are alive at time $t$, i.e. the cohorts $s \in\left[t-t_{D}, t\right]$, participate in the collective pension scheme. Such a situation could be the result of participation having been mandatory so far or of a good investment performance of the pension fund so far. We set the risk-free interest rate at $r=0.02$, the expected portfolio return at $\mu=0.05$ and the portfolio return volatility at $\sigma=0.15$. We assume that the pension fund invests $60 \%$ of its assets in stocks and $40 \%$ in bonds, which is roughly the average allocation for Dutch pension funds (Broeders et al., 2016). Hence, the expected portfolio return at $\mu=0.05$ implies that the risk premium on stocks is $\frac{\mu-r}{0.60} * 100 \%=$ $5 \%$, which is in line with the equity premium estimate of Avdis and Wachter (2016). Further, we set the regulatory smoothing parameter to a value of $\alpha=0.9$, which corresponds to the case of the Netherlands where pension funds are required to restore their financial position in a period of ten years (DNB, 2015). Our analysis is based on $Z=10^{5}$ simulation runs, each with a "burn-in" period of 100 years, after which we start evaluating the simulation results over the length of an individual's life, i.e. a period of $t_{D}=60$ years. $^{7}$ This way, we start the recording of the simulation results from a realistic setting in which the various cohorts up to now have been confronted with the investment risk. Time steps in our simulations need to be small to approximate continuous time. We set the time steps at $\delta=0.1$, implying 10 possible dates per annum to exercise the exit option when it is of the American type. For convenience, the benchmark calculations are based on a cohort that starts working immediately after the burn-in period at time $t_{0}=0$. Hence, for this cohort, which we index by $s=0$, the time index is equal to its age.

\section{The "European" exit option under a DB pension scheme}

As a stepping stone to the remainder of the analysis, this section explores the European exit option for the case of a DB pension scheme. The assumptions of DB (hence, $\omega=0$ and $\gamma_{t}=1, \forall t$ ) and full participation imply that

$c_{t-v, t}=\bar{c}_{v}+\pi_{t-v, t}=\bar{c}_{v}+\frac{\Omega_{t}+\bar{\pi}}{t_{R}}$,

\footnotetext{
6 Other parameter settings are explored in Appendix C, as a robustness check.

7 This burn-in period is intended to make the results robust for the choice of the initial parameter setting. Appendix A.3 shows that the amount of time the variance of the funding ratio converges to within $0.5 \%$ of its limit is given by $t_{0.5 \%}=$ $\frac{\log (0.005)}{2(\log \alpha) \sigma^{2}}$. Hence, by taking a burn-in period of 100 years, the second moment of the funding ratio has converged with more than $99.5 \%$ certainty to its limit for all parameter settings considered here. The most extreme setting we consider will be $\alpha=0.95$ and $\sigma=0.20$, implying $t_{0.5 \%}=85$ years. Hence, a burn-in period of 100 years is a prudent choice.
} 
Table 2

Benchmark parameter values.

\begin{tabular}{lll}
\hline Description & Symbol & Value \\
\hline Entry age & $t_{0}$ & 0 \\
Retirement age & $t_{R}$ & 40 \\
Age of death & $t_{D}$ & 60 \\
Target funding ratio & $\bar{F}$ & 1 \\
Regulatory smoothing parameter & $\alpha$ & 0.9 \\
Risk-free interest rate & $r$ & 0.02 \\
Expected portfolio return & $\mu$ & 0.05 \\
Portfolio return volatility & $\sigma$ & 0.15 \\
Wage & $w$ & 1 \\
Accrual rate & $\psi$ & $0.7 / t_{R}$ \\
\hline
\end{tabular}

while pension entitlements grow at a constant speed over an individual's working career

$$
\begin{aligned}
B_{s, t} & = \begin{cases}\psi(t-s), & \text { for }(t-s) \in\left[0, t_{R}\right], \\
B_{s, s+t_{R},} & \text { for }(t-s) \in\left(t_{R}, t_{D}\right), \\
0, & \text { otherwise. }\end{cases} \\
& = \begin{cases}\psi \min \left(t-s, t_{R}\right), & \text { for }(t-s) \in\left[0, t_{D}\right), \\
0, & \text { otherwise. }\end{cases}
\end{aligned}
$$

Hence, a retiree's pension benefit is simply the accrual rate multiplied by the years of service $\left(\psi t_{R}\right)$. The constant benefit during retirement and the full participation imply that liabilities are always equal to their equilibrium value, i.e. $d L_{t}=0$. In Appendix A.5 we show that

$\pi_{t-v, t}=\frac{\left(A_{t}-\bar{L}\right)[(\log \alpha)-\mu]+\bar{\pi}}{t_{R}}$.

Note that $-\log \alpha>0$. Hence, the recovery contribution is increasing in the shortfall of the pension fund's assets from its liabilities, decreasing in the number $t_{R}$ of working cohorts that need to close this shortfall and increasing in the difference between the risk-free interest rate, $r$, and the logarithm of the smoothing parameter. An increase in the smoothing parameter implies that the funding gap can be closed at a lower speed and, hence, the recovery contribution can be reduced for a given gap $\bar{L}-A_{t}$. In the special, non-admitted case of $\alpha=1$ there would be no attempt to reduce the gap $\bar{L}-A_{t}$ and the restoration contribution simply equals the expected investment return on the gap of the pension fund.

Under the European option there is a specific age at which individuals of a cohort of age $t_{M}$ are allowed to once and for all decide to exit the pension fund. To keep the computations tractable, here and in the following, we assume that the decision whether to exit, or not, is taken under myopic beliefs, i.e. under the myopic assumption that all the other cohorts will decide to stay in the pension fund. While this assumption is clearly not fully realistic, the opposite assumption of full rationality is also not realistic, since it would require individuals to think through the decisions of all the other participants and how this impacts the financial situation of the pension fund. The average pension fund participant surely features some myopia. Our assumption of myopia may be a useful starting point for further refinement. In addition, it serves tractability. If, instead, we would assume full rationality, we would, after discretizing the model into a large number of cohorts, need to simulate out the consequences of all future exits of all possible combinations of cohorts. This would be computationally too demanding, while one could moreover ask how realistic is it to allow for individuals to fully think through all possible future eventualities.

A cohort $s$ worker of age $t_{M}$ continues to participate in the scheme when the so-called "net value of participation" is positive. This is the discounted value of his future pension benefits, $\exp \left[-r\left(t_{R}-t_{M}\right)\right] \Pi_{s+t_{R}}\left(B_{s, s+t_{R}}\right)$, minus the expected discounted sum of the contributions to be paid from now until retirement, $E_{s+t_{M}}^{\mathbb{Q}}\left[\int_{t_{M}}^{t_{R}} c_{s+u} \exp \left[-r\left(u-t_{M}\right)\right] d u\right]$, minus the payout received upon exiting, $\min \left(1, F_{s+t_{M}}\right) \Pi_{s+t_{M}}\left(B_{s, s+t_{M}}\right)$. Hence, the net value of participation is given by

$$
\begin{aligned}
\operatorname{Part}_{s, s+t_{M}}= & \exp \left[-r\left(t_{R}-t_{M}\right)\right] \Pi_{s+t_{R}}\left(B_{s, s+t_{R}}\right) \\
& -E_{s+t_{M}}^{\mathbb{Q}}\left[\int_{t_{M}}^{t_{R}} c_{s+u} \exp \left[-r\left(u-t_{M}\right)\right] d u\right] \\
& -\min \left(1, F_{s+t_{M}}\right) \Pi_{s+t_{M}}\left(B_{s, s+t_{M}}\right) .
\end{aligned}
$$

Appendix A.6 shows that if $F_{s+t_{M}}=1$, then Part $_{s, s+t_{M}}>0$ and $\partial$ Part $_{s, s+t_{M}} / \partial F_{s+t_{M}}>0$. Hence, the net value of participation is strictly positive for funding ratios above one. Specifically, the net value of participation at the retirement age, obtained by setting $t_{M}=t_{R}$, is

$\operatorname{Part}_{s, s+t_{R}}=\Pi_{s+t_{R}}\left(B_{s, s+t_{R}}\right) \max \left(0,1-F_{s+t_{R}}\right) \geq 0$.

Hence, the net value of participation at the retirement age can never be negative under a $\mathrm{DB}$ pension scheme. It becomes strictly positive with underfunding, because under the alternative of exiting, a fraction of the pension entitlements would have to be given up.

Appendix A.6 also derives that

$$
\begin{aligned}
\operatorname{Part}_{s, s+t_{M}}= & {\left[\exp \left(-r t_{R}\right)-\exp \left(-r t_{D}\right)\right] \frac{\exp \left(r t_{M}\right) \psi t_{M}}{r} } \\
& \times \max \left(0,1-F_{s+t_{M}}\right) \\
& +\bar{L} \frac{1-\exp \left[-(\mu-\log \alpha)\left(t_{R}-t_{M}\right)\right]}{t_{R}}\left(F_{s+t_{M}}-1\right) \\
& +\frac{\bar{L}(\mu-r)}{t_{R}(\mu-r-\log \alpha)}\left\{\exp \left[-r\left(t_{R}-t_{M}\right)\right]\right. \\
& \left.-\exp \left[-(\mu-\log \alpha)\left(t_{R}-t_{M}\right)\right]\right\} .
\end{aligned}
$$

Calculated from Eq. (9), we obtain the participation threshold on the funding ratio as a function of age, which is depicted by the dashed line in Fig. 1(b). The participation threshold is the value of the funding ratio at which the net value of participation is zero, while it is positive for larger funding ratios. If the funding ratio falls below this threshold, it is optimal for the participant to exercise his exit option. On the right-hand side of Eq. (9) the first term is decreasing in the funding ratio when it is lower than $100 \%$, reflecting the fact that exiting becomes relatively more attractive when fewer entitlements need to be given up. The second line is increasing in the funding ratio, because a higher funding ratio reduces the expected need for restoration measures when participating in the pension fund. The final line is increasing in the pension fund risk premium $(\mu-r)$ (holding $\mu$ and $r$ constant in the remainder of expression (9)). In particular, in the absence of a risk premium, the participation threshold would irrespective of age be constant at $100 \%$. However, in our case with $\mu-r=0.03$, the participation threshold is below $100 \%$, as the risk premium makes participation more attractive. Specifically, for a cohort entering the pension fund at the start of its working life, the threshold is at a funding ratio of $90.1 \%$. For a positive risk premium it decreases with age.

\section{The "American" exit option}

From now on the participant has the possibility to exit at any moment until retirement. The enhanced opportunities for exercising it renders the American exit option more valuable than the European option considered in the previous section. Ceteris paribus, this raises the net value of participation in the pension fund. To approximate the net value of participation 


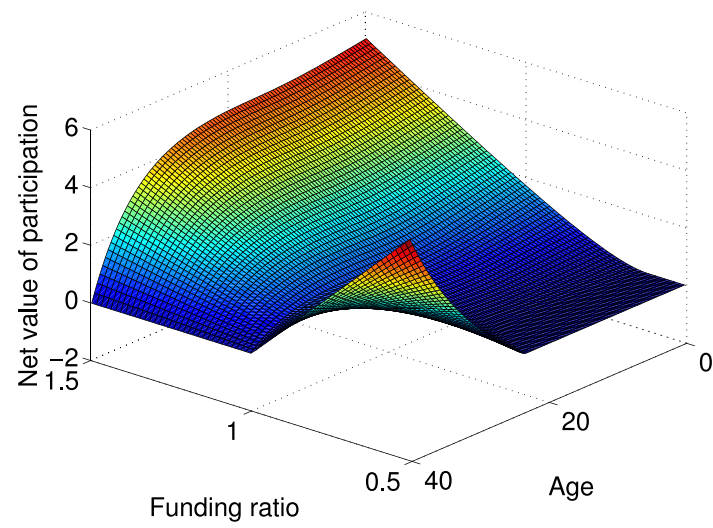

(a) Net value of participation.

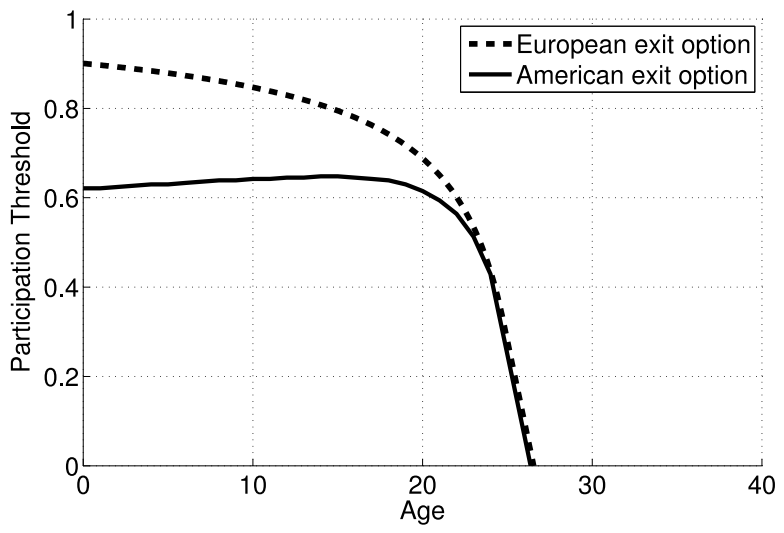

(b) Participation thresholds at different ages.

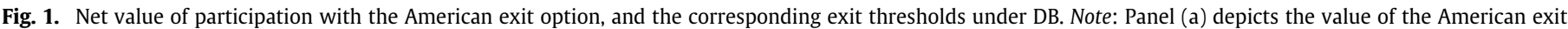

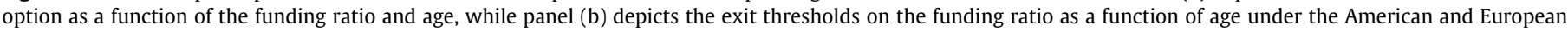
options.

under the American option, we choose a fine partition $t \in$ $\left\{t_{0}, t_{0}+\delta, t_{0}+2 \delta, \ldots, t_{R}\right\}$ for the possible exercise dates. An analytical expression for the net value of participation would be cumbersome to derive algebraically, if this is at all possible. Therefore, we approximate it. For the $\mathrm{CDC}$ and hybrid pension schemes, there are multiple state variables affecting the value of the American option. Hence, we use the so-called Least Squares Monte Carlo (LSMC) approximation method to determine the option value for these pension arrangements. For the DB pension scheme, there is a single state variable. In this case, more accurate results can be obtained using a finite-difference (FD) computation. Hence, in the remainder we apply the explicit finite difference (FD) method to analyse the DB pension scheme and the LSMC method to analyse the CDC and hybrid pension schemes. We explain the details of the application of these methods to the current analysis in Appendix B.

\subsection{A defined-benefit pension scheme}

We first consider the DB pension scheme with guaranteed benefits. Therefore, the only variable relevant for the participation decision is the assets of the pension fund $A_{t}$. At maturity, i.c. the retirement age $t_{R}$, the net value of participation is given by Eq. (8). Appendix B.1 shows that we can approximate the value $(V)$ of some option recursively using the Black-Scholes partial differential equation

$\frac{\partial V}{\partial t}=-\frac{1}{2}(\sigma A)^{2} \frac{\partial^{2} V}{\partial^{2} A}-(\log \alpha)(A-\bar{L}) \frac{\partial V}{\partial A}+r V$.

At each grid point combination $\left(A_{i}, t_{j}\right)$ of assets and age, we now determine whether it is optimal to exit by exercising the option or whether it is optimal to stay in the fund by paying the contributions. Hence, the value of the option is given by the recursion

$V_{i, j} \leftarrow \max \left\{V_{i, j}-E_{t_{j}}^{\mathbb{Q}}\left[\int_{j}^{j+1} c\left(A_{i}, t_{j}\right) d u\right], \Theta\left(A_{i}, t_{j}\right)\right\}$,

where the value obtained from exiting at age $v$ with assets $A$ is given by

$\Theta\left(A_{i}, t_{j}\right)=\min \left(1, A_{i} / \bar{L}\right) \Pi_{t}\left(B_{t-t_{j}, t}\right)$.

Fig. 1(a) depicts, as a function of the funding ratio and age, the net value of participation Part $_{i, j}=V_{i, j}-E_{t_{j}}^{\mathbb{Q}}\left[\int_{j}^{j+1} c\left(A_{i}, t_{j}\right) d u\right]-$ $\Theta\left(A_{i}, t_{j}\right)$, i.e. the value of the American option minus the contributions minus the lump sum that can be taken out when exiting. At age $t_{R}=40$, the net value of participation is zero for funding ratios above $100 \%$, as participants are indifferent between continuing to participate or to exit, and strictly positive with underfunding-recall Eq. (8). For lower ages, the net value of participation is increasing with the funding ratio when the funding ratio is above the participation threshold. ${ }^{8}$

The solid line in Fig. 1(b) depicts for the American exit option the participation threshold on the funding ratio as a function of age. Due to the right to exit at any age up to retirement, the participation threshold is as low as $62.1 \%$ for an entry cohort, which is substantially below the original threshold of $90.1 \%$ under the European option-compare with the dashed line in Fig. 1(b). The participant makes a trade-off. Assume that the funding ratio is below one. A lower funding ratio implies higher recovery contributions associated with staying with the fund, while exiting the fund implies the loss of a larger fraction $\left(1-F_{t}\right)$ of the pension entitlements. However, this loss is small when the participant is young, because he has barely accumulated any pension entitlements. While for the European option the participation threshold is monotonically declining with age, because of the larger amount of resources to be given up when exiting and the falling expected discounted sum of restoration contributions to be paid for a given degree of underfunding as the participant gets closer to retirement, for the American option we see that the participation threshold is initially increasing. Apparently, in this case up to a certain age the shrinking value of the option as one grows older dominates the other factors driving the participation threshold. The difference between the European and the American thresholds is strictly decreasing. In fact, at entry participants have a call option on the assets of the fund, because they would obtain a zero pay off from exiting, while the net value of participation is positive when the funding ratio exceeds $62.1 \%$. Hence, when underfunding at entry is only limited, the benefit of staying in

\footnotetext{
8 Strictly speaking, the net value of participation as calculated here can become slightly negative, because of the need to discretize the age span over which the calculations are done. However, the step size is small $\left(\delta_{t}=10^{-4}\right)$. Hence, the contribution term $E_{t}^{\mathbb{Q}}\left[\int_{j}^{j+1} c\left(A_{i}, t_{j}\right) d u\right]$ is close to zero. If the step size converges to zero, this term also shrinks to zero, and the net value of participation can no longer fall below zero. The algorithm is such that, once the net value of participation reaches its slightly negative value, the exit option is exercised. Under the LSMC method used below, for reasons of computer working memory limitations the time steps are larger than under the FD method and, hence, the net value of participation can fall slightly further below zero. However, if it were possible to shrink the step size to zero also here the minimum of the net value of participation would be zero.
} 
Table 3

Least-squares approximation of the net value of participation.

\begin{tabular}{|c|c|c|c|c|c|c|c|c|c|c|}
\hline Age $(t-s)$ & 0 & 10 & 20 & 30 & 40 & 0 & 10 & 20 & 30 & 40 \\
\hline & \multicolumn{5}{|c|}{$\omega=0.25$ (hybrid) } & \multicolumn{5}{|c|}{$\omega=0.5$ (hybrid) } \\
\hline$\hat{\beta}_{t-s, 1}$ & 4.476 & 3.814 & 6.851 & 8.742 & -7.454 & 4.581 & 4.803 & 4.881 & 5.440 & -5.807 \\
\hline$\hat{\beta}_{t-s, F}$ & -4.403 & -4.598 & -4.309 & -1.063 & 7.941 & -2.933 & -5.067 & -2.891 & -2.788 & 6.754 \\
\hline$\hat{\beta}_{t-s, F^{2}}$ & 1.917 & 1.471 & 1.602 & -0.621 & -1.191 & 1.311 & 1.775 & 0.710 & 0.078 & -1.765 \\
\hline$\hat{\beta}_{t-s, \max (1-F, 0)}$ & -0.909 & 0.500 & 3.664 & 7.664 & 10.644 & -0.595 & 0.531 & 3.829 & 7.021 & 8.358 \\
\hline$\hat{\beta}_{t-s, L}$ & -0.017 & -0.099 & -0.187 & -0.210 & -0.312 & 0.016 & -0.055 & -0.133 & -0.156 & -0.335 \\
\hline$\hat{\beta}_{t-s, L^{2}} * 10^{5}$ & 0.486 & 2.568 & 4.678 & 9.362 & -0.412 & -0.165 & 1.117 & 2.592 & 4.539 & 0.037 \\
\hline$\hat{\beta}_{t-s, A}$ & 0.020 & 0.023 & 0.024 & 0.030 & -0.009 & 0.015 & 0.018 & 0.021 & 0.027 & 0.004 \\
\hline$\hat{\beta}_{t-s, B_{10}}$ & 5.401 & 20.910 & -4.932 & 15.682 & 39.788 & 2.732 & 13.435 & -2.629 & 12.928 & 35.272 \\
\hline$\hat{\beta}_{t-s, B_{20}}$ & 0.854 & 9.610 & 28.675 & -11.782 & 47.961 & -3.233 & 6.307 & 22.769 & -13.172 & 47.976 \\
\hline$\hat{\beta}_{t-s, B_{30}}$ & -3.206 & 9.253 & 22.978 & 37.409 & -28.068 & -3.604 & 4.954 & 17.111 & 35.390 & -30.694 \\
\hline$\hat{\beta}_{t-s, B_{40}}$ & -5.627 & 1.441 & 15.845 & 20.599 & 98.980 & -11.378 & -2.716 & 9.098 & 17.688 & 112.206 \\
\hline$\hat{\beta}_{t-s, B_{50}}$ & 3.563 & 11.015 & 15.265 & 10.939 & 31.040 & 2.594 & 8.205 & 12.450 & 8.102 & 25.529 \\
\hline$\left(\frac{\partial \operatorname{Part}_{s, t}^{\mathbb{Q}}}{\partial F}\right)$ & 6.530 & 4.826 & 2.636 & -0.810 & -7.879 & 4.677 & 3.487 & 1.032 & -1.468 & -3.868 \\
\hline \multirow{2}{*}{$\left(\frac{\partial \operatorname{Part}_{s, t}^{\mathbb{Q}}}{\partial F}\right)_{+}$} & 5.621 & 5.325 & 6.300 & 6.854 & 2.765 & 4.082 & 4.018 & 4.860 & 5.553 & 4.490 \\
\hline & \multicolumn{5}{|c|}{$\omega=0.75$ (hybrid) } & \multicolumn{5}{|c|}{$\omega=1$ (Collective DC) } \\
\hline$\hat{\beta}_{t-s, 1}$ & 4.040 & 4.985 & 3.899 & 6.169 & -1.577 & 4.204 & 4.614 & 3.868 & 5.546 & 2.048 \\
\hline$\hat{\beta}_{t-s, F}$ & -0.038 & -3.863 & -0.941 & -5.524 & 3.854 & -1.527 & -5.186 & 3.932 & -2.137 & 2.796 \\
\hline$\hat{\beta}_{t-s, F^{2}}$ & 0.018 & 1.192 & -0.162 & 1.250 & -1.960 & 0.617 & 1.829 & -4.330 & -1.012 & -2.735 \\
\hline$\hat{\beta}_{t-s, \max (1-F, 0)}$ & -0.177 & 0.840 & 3.683 & 5.893 & 6.199 & -1.099 & 1.327 & 6.832 & 4.946 & 4.649 \\
\hline$\hat{\beta}_{t-s, L}$ & 0.003 & -0.058 & -0.133 & -0.168 & -0.370 & 0.155 & 0.138 & -0.700 & -0.466 & -0.082 \\
\hline$\hat{\beta}_{t-s, L^{2}} * 10^{5}$ & -0.459 & 0.624 & 2.072 & 2.898 & 0.863 & -0.237 & -0.859 & -0.001 & 2.677 & 0.785 \\
\hline$\hat{\beta}_{t-s, A}$ & 0.008 & 0.016 & 0.016 & 0.026 & 0.025 & -0.003 & 0.022 & 0.059 & 0.050 & 0.046 \\
\hline$\hat{\beta}_{t-s, B_{10}}$ & 2.524 & 12.854 & -4.081 & 16.297 & 32.741 & 4.007 & -2.660 & 20.103 & 42.541 & -15.999 \\
\hline$\hat{\beta}_{t-s, B_{20}}$ & -1.308 & 6.562 & 29.320 & -21.605 & 48.087 & -28.759 & -8.298 & 122.627 & -37.993 & 1.780 \\
\hline$\hat{\beta}_{t-s, B_{30}}$ & -1.318 & 4.734 & 15.188 & 50.866 & -29.663 & -13.490 & -41.774 & 66.477 & 180.755 & -60.421 \\
\hline$\hat{\beta}_{t-s, B_{40}}$ & -3.786 & 2.828 & 11.435 & 19.180 & 116.500 & -30.052 & -15.542 & 90.719 & 4.507 & 86.724 \\
\hline$\hat{\beta}_{t-s, B_{50}}$ & 2.456 & 6.788 & 12.772 & 9.163 & 25.935 & -10.355 & -12.686 & 75.912 & 47.060 & -19.391 \\
\hline$\left(\frac{\partial \text { Part }_{s, t}^{\mathbb{Q}}}{\partial F}\right)$ & 2.709 & 2.533 & -0.043 & -1.056 & 1.321 & 0.022 & 3.836 & 6.345 & 6.134 & 6.688 \\
\hline$\left(\frac{\partial \text { Part }_{s, t}^{\mathbb{Q}}}{\partial F}\right)_{+}$ & 2.532 & 3.374 & 3.640 & 4.838 & 7.520 & -1.078 & 5.163 & 13.177 & 11.080 & 11.337 \\
\hline
\end{tabular}

Note: This table reports the coefficients of the least-squares approximation by Eq. (10) of the net value of participation under the American exit option.

the fund outweighs the cost associated with restoring the funding ratio. Because the value of the option is higher the longer the period over which it can be exercised, the difference between the thresholds of the European and the American option decreases with age and converges to zero when age rises.

\section{2. $C D C$ and hybrid pension schemes}

Now, we turn to the CDC and hybrid pension schemes. Under the former, the only policy instrument is the indexation rate. Under the latter, the pension fund uses both recovery contributions and the indexation rate as instruments. The retirement benefits are uncertain, because the indexation rate is uncertain. While in the case of the DB pension scheme the participation decision only depends on the funding ratio, it now depends on a wider set of state variables. To see this, suppose, for example, that we fix the funding ratio at $100 \%$ and vary the pension entitlements of the very old. If these entitlements are relatively low, then the pension fund's liabilities can be expected to increase, because the average level of the entitlements will rise once the low entitlements of the very old have been fully paid out and replaced by the newly acquired entitlements of the younger cohorts. An increase in the (average) liabilities will lead to reduced future indexation. Hence, it becomes relatively more attractive for active cohorts to exit. The opposite is the case when the entitlements of the very old are relatively high for given funding ratio.
We approximate the net value of participation of cohort $s$ using a linear function that is given in Box I: where $1_{Z}$ is a vector of length $Z$ filled with ones. Note that the vector $\beta_{t-s} \equiv\left(\beta_{t-s, 1}, \beta_{t-s, F}, \ldots\right)^{\prime}$ is age-dependent. This model fits the net value of participation as a function of a linear and quadratic term of the funding ratio $\left(F_{t}\right)$, the extent of underfunding, i.e. $\max \left(1-F_{t}, 0\right)$, a linear and quadratic term of the liabilities $\left(L_{t}\right)$, an interaction term $\left(F_{t} L_{t}=A_{t}\right)$ and the entitlements of a limited number of cohorts. We do not include the entitlements of all the cohorts, as this increases the computational burden substantially. Since the entitlements of cohorts close in age are similar, we would expect only small improvements in the approximation when we include the pension entitlements of more cohorts. In Appendix C. 1 we show that the outcomes are hardly affected by including the pension entitlements of more cohorts. In addition, we exclude $B_{t, t}$, since the pension entitlements are zero at entry, while we also exclude the pension entitlements of the deceased generation at time $t, B_{t-t_{D}, t}$. We denote by $\hat{\beta}_{t-s}$ the vector that minimizes the sum of the least-squares errors in the approximation of the net value of participation by (10).

Table 3 reports $\hat{\beta}_{t-s}$ for different ages and different values of the hybridity parameter $\omega$. Moreover, in order to capture the full marginal effect of the funding ratio on the net value of participation, underneath each panel, we report the following two statistics that are obtained by varying the funding ratio around its equilibrium level, while keeping the liabilities and the pension entitlements at their equilibrium values. We refer to 


$$
\begin{aligned}
\operatorname{Part}_{s, t}^{\mathbb{Q}} & \approx X_{t}^{\prime} \beta_{t-s}, \\
\text { with } X_{t} & =\left[\begin{array}{lllllllllll}
1_{Z} & F_{t} & F_{t}^{2} & \max \left(1-F_{t}, 0\right) & L_{t} & L_{t}^{2} & \underbrace{F_{t} L_{t}}_{=A_{t}} & B_{t-10, t} & B_{t-20, t} & \cdots & B_{t-50, t}
\end{array}\right]
\end{aligned}
$$

Box I.

these statistics as the "total coefficients of the funding ratio" in approximation (10):

$$
\begin{aligned}
\left(\frac{\partial \operatorname{Part}_{s, t}^{\mathbb{Q}}}{\partial F}\right)_{-} & \equiv \lim _{h \uparrow 0} \frac{\operatorname{Part}(\bar{F})-\operatorname{Part}(\bar{F}-h)}{h} \\
& \approx \hat{\beta}_{t-s, F}+2 \hat{\beta}_{t-s, F^{2}}+\hat{\beta}_{t-s, A} \bar{L}-\hat{\beta}_{t-s, \max (1-F, 0)} \\
\left(\frac{\partial \operatorname{Part}_{s, t}^{\mathbb{Q}}}{\partial F}\right)_{+} & \equiv \lim _{h \downarrow 0} \frac{\operatorname{Part}(\bar{F}+h)-\operatorname{Part}(\bar{F})}{h} \\
& \approx \hat{\beta}_{t-s, F}+2 \hat{\beta}_{t-s, F^{2}}+\hat{\beta}_{t-s, A} \bar{L}
\end{aligned}
$$

where we have assumed that the marginal impact of the funding ratio on the error of the least-squares approximation is negligible.

Due to the rule whereby part of the pension entitlements are given up by exercising the option, the net value of participation as a function of the funding ratio exhibits a kink at $F=100 \%$. The approximated difference in the slope of the total coefficients is determined by the coefficient $\hat{\beta}_{t-s, \max (1-F, 0)}$. In the case of over-funding, an increase in the funding ratio has no effect on the alternative of exiting, because the participant cannot take out more value when exiting, while the participant benefits fully from the reduction in contributions and/or the higher indexation allowed for by the higher funding ratio. In the case of underfunding, this latter effect is also present, but now the alternative of exiting becomes relatively more attractive, and thus continuing to participate becomes relatively less attractive, as more value can be taken out of the pension fund when the funding ratio increases. As age increases, for a sufficiently high hybridity parameter $\omega$ the total coefficient on the funding ratio tends to increase in the case of over-funding. The likelihood that the participant decides to exit the pension fund before the option matures shrinks, so the benefits of over-funding through more indexation can more likely be enjoyed also after retirement. Further, the difference between the total coefficients increases with age, because the coefficient on the degree of underfunding, $\max (1-F, 0)$, is rising with age. Because older participants have accumulated more pension entitlements, also more are lost when the exit option is exercised at a given degree of underfunding.

There are other interesting observations to be made from Table 3. For pension arrangements sufficiently close to CDC there is some tendency for the coefficients on the pension entitlements of the own-age cohort to have the largest value, in line with the intuition that the net value of participation to an individual is affected most by his own pension entitlements. Finally, we saw that exiting close before the retirement age would never be optimal under the $\mathrm{DB}$ pension scheme. However, under a $\mathrm{CDC}$ pension scheme or a hybrid pension scheme, it could be optimal to exit at the retirement age, as indexation policy can affect retirement income negatively. ${ }^{9}$ This is the case in particular for combinations of low funding ratios and low own pension entitlements. In the case of underfunding, the older worker who stays can be expected

\footnotetext{
9 For example, when the pension entitlements of a cohort of age $t_{R}$ are low, because of some bad years that caused low indexation in the past, then the vector of coefficients $\hat{\beta}_{40}$ can imply that $\hat{P a r t}_{s, t}=X_{t}^{\prime} \hat{\beta}_{40}<0$. This is not the case under the DB pension scheme, where the pension entitlements are constant.
}

to make a large contribution to restoring the pension fund's financial health through reduced indexation. This effect is not prevalent when the participants' own pension entitlements are high-remember that the lump-sum that he gets when he exits is linked to both his own entitlements and the funding ratio. ${ }^{10}$

\subsection{Exit distribution under the collective pension scheme}

So far we have focused on valuation of the exit option. In this section we explore the likelihood of participants from different cohorts to exercise their exit option. We simulate the Radon-Nikodym derivative along each simulation path, which we can use to transform the approximated probabilities of exiting under the risk-neutral measure $\mathbb{Q}$ into the corresponding probabilities of exiting under the "real-world" measure $\mathbb{P}$. The Radon-Nikodym derivative at time $t$ is given by

$\left(\frac{d \mathbb{P}}{d \mathbb{Q}}\right)_{t}=\Lambda_{t}=\exp \left(\lambda W_{t}^{\mathbb{Q}}-\frac{t}{2} \lambda^{2}\right)$.

Fig. 2 presents these probabilities as a function of age for different values of the hybridity parameter $\omega$, the regulatory smoothing parameter $\alpha$ and the investment risk parameter $\sigma$. In each simulation run immediately after the burn-in period we check for each cohort whether the net value of participation becomes negative. Hence, the figure shows for each age the frequency with which the net value of participation would become negative and thus trigger the exercise of the exit option.

In the left panels of Fig. 2 we vary the regulatory smoothing parameter $\alpha$, while in the right panels we vary the investment risk parameter $\sigma$. The probabilities of exiting under the DB pension scheme $(\omega=0)$ are presented in panels (a) and (b). Shortly before retirement it is never optimal to exit, resulting in exit probabilities equal to zero. In panel (a) we observe that the likelihood that older workers exit falls with the smoothing parameter. More smoothing shifts more of the recovery burden to future contributors, encouraging older workers to stay in the fund. The opposite holds for younger workers: we observe that a higher value of the smoothing parameter increases their likelihood to exit. In panel (b) we observe that higher investment risk raises the likelihood of cohorts exiting.

Panels (c)-(f) depict the probabilities of exiting under a hybrid pension scheme $(\omega=0.5)$ and a CDC pension scheme $(\omega=$ $1)$. Under the DB pension scheme elderly workers are unlikely to exit, while the opposite holds for the hybrid and CDC pension scheme, where young workers are unlikely to exit. Again, an increase in the investment risk parameter $\sigma$ tends to make exit more likely. For the regulatory smoothing parameter there is a trade-off. More smoothing implies less aggressive adjustments in the contribution and/or indexation policies to close the funding gap, but it also implies larger fluctuations in the funding ratio. Apparently, the disadvantage of the larger fluctuations in the funding ratio dominates, as exiting becomes more likely when there is more smoothing.

10 To see this very concretely, take the final column of Table 3 (age $=40, \omega=1$ ). Then, when all variables are at equilibrium values, we get Part $=X_{t}^{\prime} \hat{\beta}_{40}=1.90>0$, so exercising the option would not be optimal. However, if we change the pension entitlements of a cohort of age $t_{R}$ to $0.95 t_{R} \psi$, so to $5 \%$ below the equilibrium value, while leaving all other variables at their equilibrium level, then Part $=X_{t}^{\prime} \hat{\beta}_{40}=$ $-1.14<0$, so exercising is optimal. 


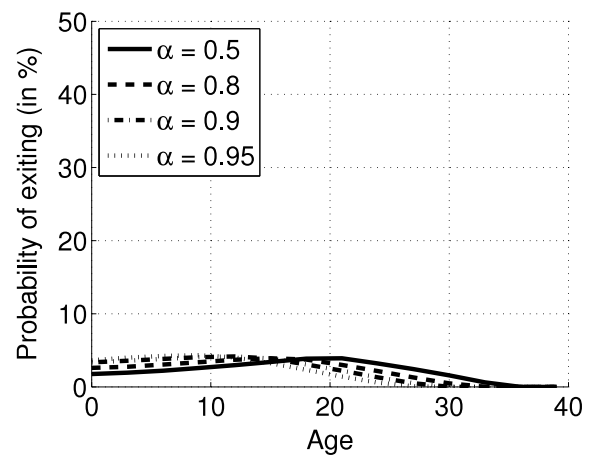

(a) DB pension scheme $(\omega=0)$.

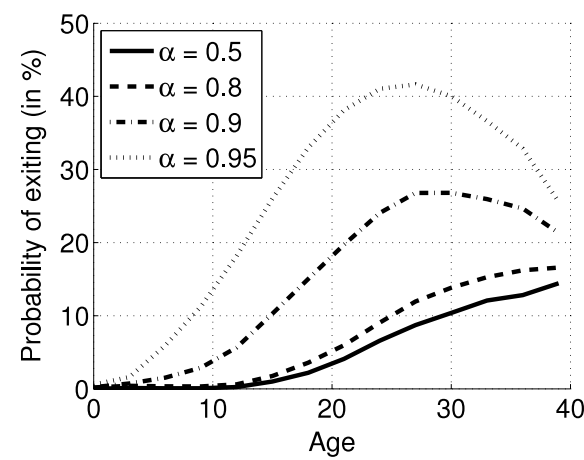

(c) Hybrid pension scheme $(\omega=0.5)$.

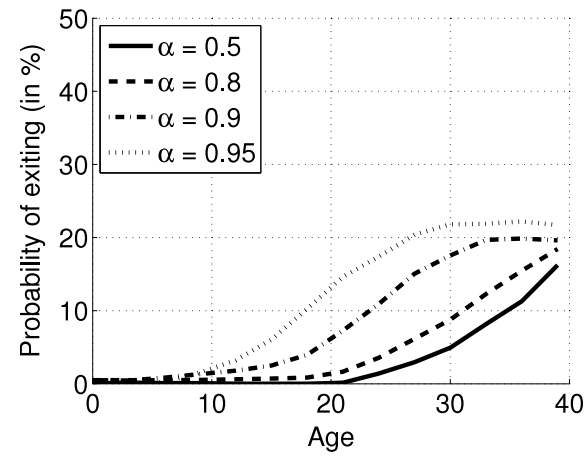

(e) CDC pension scheme $(\omega=1)$.

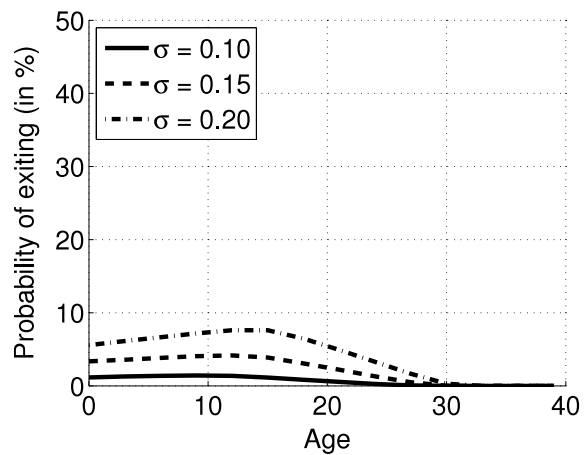

(b) DB pension scheme $(\omega=0)$.

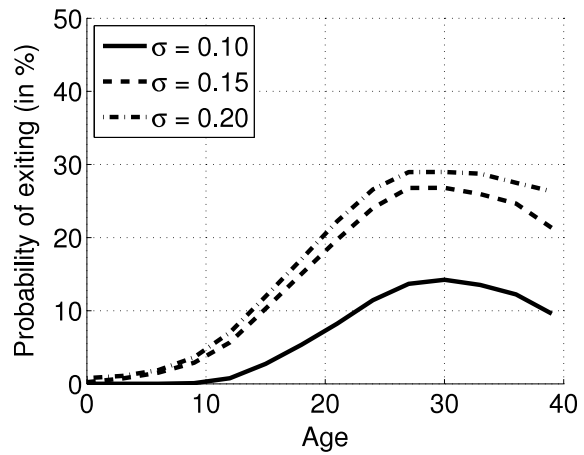

(d) Hybrid pension scheme $(\omega=0.5)$.

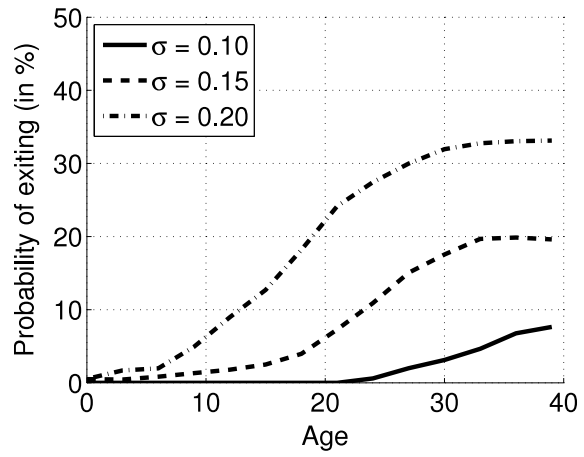

(f) CDC pension scheme $(\omega=1)$.

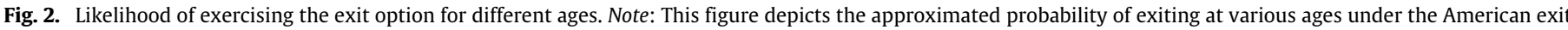
option for different combinations of the hybridity parameter $\omega$, regulatory smoothing parameter $\alpha$ and investment risk $\sigma$.

\section{Uniform contribution policies}

So far, we have considered age-dependent contributions. However, in reality collective pension schemes usually rely on uniform contributions, i.e. contributions that are independent of age in particular. Uniform contributions are typically applied in DB pension schemes, such as the public sector pension plans in Australia, Canada, Germany, the Netherlands, Norway and Switzerland, the Universities Superannuation Scheme in the UK and the subnational civil servants' plans in the US (Ponds et al., 2011; Westerhout et al., 2014; OECD, 2001). Uniform contributions are not actuarially fair, because young workers typically pay more, while elderly workers typically pay less than the present discounted value of their expected future benefits. Because a uniform contribution policy benefits older workers at the expense of younger workers, we expect that the likelihood of older workers exiting falls. By contrast, younger workers have a more valuable exit option, which should discourage them from exiting. In this section we explore first the $\mathrm{DB}$ pension scheme and then the $\mathrm{CDC}$ and hybrid pension schemes under uniform contributions. Then, we study a compromise between the uniform and our original age-dependent contribution policies to see whether we can find settings in which the likelihood that no cohort wants to leave the pension scheme can be raised when compared with these two special cases.

The uniform contribution is given by

$$
c_{s, t}=\bar{c}+\pi_{s, t}^{\text {unif }},
$$

where $\bar{c} t_{R}=\psi \bar{R}$ and $\pi_{s, t}^{u n i f}=\frac{(1-\omega) \Omega_{t}+\bar{\pi}}{\int_{I_{t}^{w}} 1 d s}$.

The component $\pi_{s, t}^{\text {unif }}$ is identical for all working cohorts and arises from the need to bring the funding ratio towards its long-run 


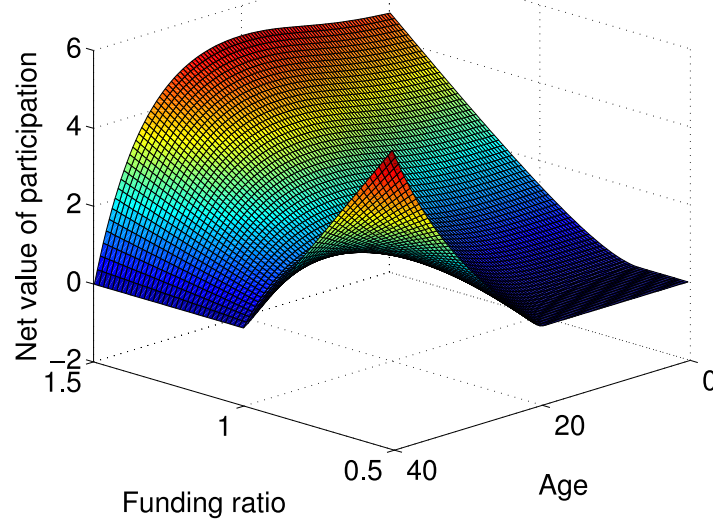

(a) Net value of participation.

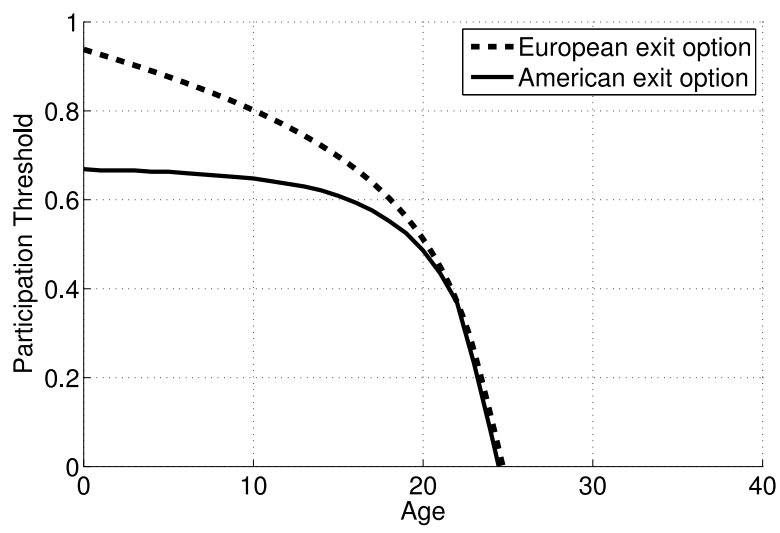

(b) Participation thresholds at different ages.

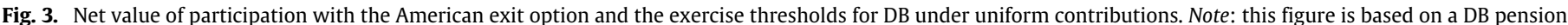

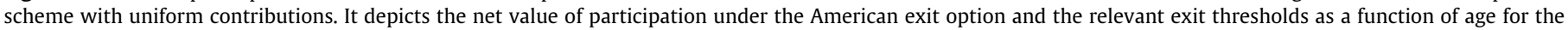
European and American exit options.

average target. Hence, equilibrium aggregate contributions $\left(\bar{c} t_{R}\right)$ are equal to the market price of the total pension accrual.

\subsection{The defined-benefit pension scheme}

We start with the $\mathrm{DB}$ pension scheme, setting $\omega=0$ in Eq. (12). Hence, $\gamma_{t}=1, \forall t$, so that pension entitlements grow uniformly over an individual's working career-see Eq. (6). Fig. 3(a) depicts, as a function of the funding ratio and age, the net value of participation under the American exit option. Again, at age $t_{R}=40$, the net value of participation is zero when the funding ratio exceeds $100 \%$, while it is strictly positive when there is underfunding. Also, for lower ages the net value of participation is again increasing with the funding ratio.

Appendix A.6.2 derives the participation thresholds analytically as a function of age for the European exit option. These are depicted by the dashed line in panel (b). The threshold of an entry cohort now exceeds the original threshold of $90.1 \%$ (recall Fig. 1(b)), because the uniform contribution benefits older workers at the expense of younger workers. The threshold decreases faster than before with age. For the American exit option, we again use the explicit FD approximation method. The solid line in panel (b) represents the participation thresholds under this option. Again, because the value of the American exit option is higher when the period over which the option can be exercised is longer, the difference between the dashed line, starting at an entry threshold funding ratio of $93.8 \%$, and the solid line, starting at an entry a threshold funding ratio of $66.9 \%$, is largest at the entry age.

\subsection{The $C D C$ and Hybrid pension schemes}

This subsection turns to the other pension arrangements. Table 4 reports the coefficients of (10) that minimize the sum of the least-squares errors in the approximation of the net value of participation for different ages and values of the hybridity parameter. The results largely correspond with those under the age-dependent contribution reported in Table 3. First, the difference between the total coefficients on the funding ratio, $\left(\partial \operatorname{Part}_{s, t}^{\mathbb{Q}} / \partial F\right)_{-}$and $\left(\partial \operatorname{Part}_{s, t}^{\mathbb{Q}} / \partial F\right)_{+}$in the case of over, respectively underfunding, is again determined by the approximated coefficient on the extent of underfunding $\hat{\beta}_{t-s, \max (1-F, 0)}$. This coefficient generally increases with age, because older participants have accumulated more pension entitlements and, therefore, they give up more of their potential retirement income when exiting in the case of underfunding. Second, as before, when the pension scheme relies relatively heavily on recovery through indexation adjustments, there is some tendency for the net value of participation to be mostly affected by the pension entitlements of the cohort closest in age to the participant under consideration, particularly when age increases. Finally, while we saw in Fig. 3(b) that close to and at retirement date it would never be optimal to exit the DB pension scheme, this is not the case for the CDC or hybrid schemes, as the indexation policy can negatively affect retirement income, making it potentially optimal to exit just before or at retirement. Note that the coefficients for the net value of participation at age 40 are identical to those in Table 3, because the type of contribution policy does not affect the net value of participation at the retirement age.

\subsection{Exit distribution under the collective pension scheme}

It is also interesting to analyse the probabilities of exercising the exit option under a uniform contribution policy. Analogous to Fig. 2, Fig. 4 depicts the likelihood that a participant of given age exercises its exit option.

Compared to the case of the age-dependent contribution policy, because of the implicit subsidy to the elderly workers under the DB pension scheme the probabilities of exiting are now higher at entry into the fund, while they decrease faster with age-see panels (a) and (b). For the hybrid and CDC pension schemes, see panels (c)-(f), the exit likelihood is increasing with age, as the elderly workers carry a larger fraction of the recovery burden through indexation in the case of underfunding. The implicit subsidy from the uniform contribution policy results in lower exit likelihoods for the elderly workers than with age-dependent contributions. For the hybrid and CDC pension scheme the likelihood of elderly workers exiting again increases with the degree of regulatory smoothing $\alpha$. Also, higher investment risk $\sigma$ again results in higher exit likelihoods.

\subsection{Combining the age-dependent and uniform contribution policies}

The value of the American exit option discourages young workers from exiting the pension scheme, while the uniform contribution policy has the opposite effect. Using a contribution policy that forms a "compromise" between the uniform and the age-dependent contribution policy may provide the pension fund with additional flexibility to reduce the chances that any cohort wants to exit the pension fund. To explore this in detail we define a 
Table 4

Least-squares approximation of the net value of participation under a uniform contribution policy.

\begin{tabular}{|c|c|c|c|c|c|c|c|c|c|c|}
\hline Age $(t-s)$ & 0 & 10 & 20 & 30 & 40 & 0 & 10 & 20 & 30 & 40 \\
\hline & \multicolumn{5}{|c|}{$\omega=0.25$ (hybrid) } & \multicolumn{5}{|c|}{$\omega=0.5$ (hybrid) } \\
\hline$\hat{\beta}_{t-s, 1}$ & 3.558 & 3.321 & 8.075 & 9.812 & -7.454 & 3.980 & 4.938 & 5.706 & 6.338 & -5.807 \\
\hline$\hat{\beta}_{t-s, F}$ & -3.775 & -3.479 & -6.026 & -2.161 & 7.941 & -2.504 & -4.943 & -3.586 & -3.584 & 6.754 \\
\hline$\hat{\beta}_{t-s, F^{2}}$ & 2.045 & 1.073 & 2.335 & -0.280 & -1.191 & 1.175 & 1.688 & 1.053 & 0.462 & -1.765 \\
\hline$\hat{\beta}_{t-s, \max (1-F, 0)}$ & -0.690 & 0.772 & 3.119 & 7.328 & 10.644 & -0.472 & 0.663 & 3.612 & 6.878 & 8.358 \\
\hline$\hat{\beta}_{t-s, L}$ & -0.028 & -0.109 & -0.183 & -0.217 & -0.312 & 0.018 & -0.062 & -0.130 & -0.161 & -0.335 \\
\hline$\hat{\beta}_{t-s, L^{2}} * 10^{5}$ & 0.631 & 2.530 & 4.492 & 9.128 & -0.412 & -0.167 & 1.064 & 2.517 & 4.440 & 0.037 \\
\hline$\hat{\beta}_{t-s, A}$ & 0.018 & 0.022 & 0.024 & 0.031 & -0.009 & 0.014 & 0.019 & 0.021 & 0.027 & 0.004 \\
\hline$\hat{\beta}_{t-s, B_{10}}$ & 7.158 & 21.805 & -4.259 & 15.526 & 39.788 & 2.554 & 14.430 & -2.650 & 13.107 & 35.272 \\
\hline$\hat{\beta}_{t-s, B_{20}}$ & 1.827 & 11.301 & 27.755 & -11.336 & 47.961 & -3.267 & 6.900 & 22.458 & -12.468 & 47.976 \\
\hline$\hat{\beta}_{t-s, B_{30}}$ & -1.467 & 10.724 & 22.661 & 38.493 & -28.068 & -3.980 & 6.028 & 16.702 & 36.150 & -30.694 \\
\hline$\hat{\beta}_{t-s, B_{40}}$ & -4.375 & 1.974 & 15.385 & 22.168 & 98.980 & -11.847 & -2.370 & 8.890 & 18.354 & 112.206 \\
\hline$\hat{\beta}_{t-s, B_{50}}$ & 5.487 & 12.932 & 15.185 & 11.794 & 31.040 & 2.662 & 9.295 & 12.336 & 8.955 & 25.529 \\
\hline$\left(\frac{\partial \text { Part }_{s, t}^{\mathbb{Q}}}{\partial F}\right)$ & 6.473 & 4.646 & 2.934 & -0.627 & -7.879 & 4.668 & 3.375 & 1.201 & -1.349 & -3.868 \\
\hline \multirow{2}{*}{$\left(\frac{\partial \text { Part }_{s, t}^{Q}}{\partial F}\right)_{+}^{-}$} & 5.782 & 5.417 & 6.053 & 6.701 & 2.765 & 4.196 & 4.038 & 4.813 & 5.529 & 4.490 \\
\hline & \multicolumn{5}{|c|}{$\omega=0.75$ (hybrid) } & \multicolumn{5}{|c|}{$\omega=1$ (collective DC) } \\
\hline$\hat{\beta}_{t-s, 1}$ & 3.598 & 5.321 & 4.140 & 6.222 & -1.577 & 3.674 & 4.475 & 4.052 & 5.607 & 2.048 \\
\hline$\hat{\beta}_{t-s, F}$ & 0.157 & -3.999 & -0.684 & -4.894 & 3.854 & -1.338 & -4.927 & 3.963 & -1.604 & 2.796 \\
\hline$\hat{\beta}_{t-s, F^{2}}$ & -0.056 & 1.214 & -0.177 & 1.043 & -1.960 & 0.586 & 1.787 & -4.438 & -1.121 & -2.735 \\
\hline$\hat{\beta}_{t-s, \max (1-F, 0)}$ & -0.104 & 0.889 & 3.714 & 5.930 & 6.199 & -1.020 & 1.443 & 6.768 & 5.737 & 4.649 \\
\hline$\hat{\beta}_{t-s, L}$ & 0.005 & -0.059 & -0.128 & -0.165 & -0.370 & 0.162 & 0.133 & -0.634 & -0.496 & -0.082 \\
\hline$\hat{\beta}_{t-s, L^{2}} * 10^{5}$ & -0.448 & 0.606 & 2.042 & 2.841 & 0.863 & -0.265 & -0.880 & 0.011 & 2.677 & 0.785 \\
\hline$\hat{\beta}_{t-s, A}$ & 0.008 & 0.016 & 0.016 & 0.025 & 0.025 & -0.003 & 0.022 & 0.059 & 0.050 & 0.046 \\
\hline$\hat{\beta}_{t-s, B_{10}}$ & 2.262 & 12.897 & -3.722 & 15.532 & 32.741 & 3.022 & -0.941 & 14.544 & 43.995 & -15.999 \\
\hline$\hat{\beta}_{t-s, B_{20}}$ & -1.340 & 6.512 & 28.482 & -21.083 & 48.087 & -27.948 & -7.974 & 117.479 & -35.854 & 1.780 \\
\hline$\hat{\beta}_{t-s, B_{30}}$ & -1.806 & 5.005 & 14.666 & 50.014 & -29.663 & -16.039 & -39.920 & 54.696 & 187.947 & -60.421 \\
\hline$\hat{\beta}_{t-s, B_{40}}$ & -4.098 & 2.455 & 10.890 & 19.045 & 116.500 & -29.900 & -15.960 & 82.853 & 7.126 & 86.724 \\
\hline$\hat{\beta}_{t-s, B_{50}}$ & 2.297 & 7.056 & 12.517 & 8.973 & 25.935 & -11.135 & -11.607 & 67.861 & 50.586 & -19.391 \\
\hline$\left(\frac{\partial \text { Part }_{s, t}^{\mathbb{Q}}}{\partial F}\right)$ & 2.707 & 2.481 & -0.013 & -1.109 & 1.321 & 0.002 & 3.771 & 6.288 & 5.611 & 6.688 \\
\hline$\left(\frac{\partial \text { Part }_{s, t}^{Q}}{\partial F}\right)_{+}^{-}$ & 2.603 & 3.370 & 3.701 & 4.821 & 7.520 & -1.019 & 5.214 & 13.057 & 11.348 & 11.337 \\
\hline
\end{tabular}

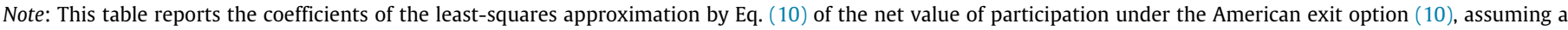
uniform contribution policy.

more general contribution policy formulated as a weighted average of the two alternatives

$c_{t-v, t}=(1-\zeta) \bar{c}+\zeta \bar{c}_{v}+\frac{(1-\omega) \Omega_{t}+\bar{\pi}}{t_{R}}$.

We refer to $\zeta$ as the "age-dependency parameter". If $\zeta=1$, the contribution policy reduces to our original age-dependent policy, while for $\zeta=0$ it is uniform. For $\zeta \in(0,1)$, the pension fund applies a compromise between these two extremes. Strictly speaking, the contribution policy is age-dependent for any $\zeta \in(0,1)$, but we define it here as a compromise. The remainder of this section explores the sustainability of a DB pension scheme, a hybrid scheme (with $\omega=0.5$ ) and a CDC scheme for different values of the agedependency parameter $(\zeta)$, the smoothing parameter $(\alpha)$ and the level of investment risk $(\sigma)$.

Table 5 reports the probability that at a given moment (immediately after the burn-in period) no participant wants to exit under the actual probability measure $\mathbb{P}$. The table yields several interesting insights. First, given the choices of the other policy parameters, the highest likelihood that all cohorts want to stay in the pension fund is obtained under the DB pension scheme. Young cohorts benefit most from the exit option, while the elderly workers have the weakest incentive to exit, as they do not bear the risk of indexation adjustments. Second, under the DB pension scheme, higher investment risk reduces the chance that none of the cohorts want to exit the pension fund. This is not the case under the hybrid scheme, where both policy instruments are used for recovery. In most cases the hybrid pension scheme features a higher probability that none of the cohorts exit when investment risk increases. Third, a trade off arises in setting the funding ratio smoothing parameter $\alpha$ to minimize the likelihood of anyone leaving the system. On the one hand, a short smoothing period stabilizes the financial position of the pension fund. On the other hand, the recovery contributions and the indexation rate fluctuate less with a long smoothing period. We observe that only when risk is low and recovery mainly relies on the contribution policy, the likelihood that no cohort exits tends to increase with the smoothing parameter. Finally, we observe that, compared to its alternatives, a uniform contribution policy tends to raise the likelihood of all cohorts preferring to stay in the fund whenever indexation is used as a recovery instrument. The reason is that, although the indexation policy makes it more likely that elderly working cohorts exercise the option to exit, the uniform contribution policy makes participation more valuable for the elderly working cohorts.

In Appendix $\mathrm{C}$ we investigate the robustness of our main results for variations in the basis function that approximates the net value of participation and for different values of the risk premium of the investment portfolio. Expanding the basis function with one additional variable at a time only has a minor impact on the likelihood that no cohort exits, while a change in the risk premium only has a rather limited effect on this likelihood. 


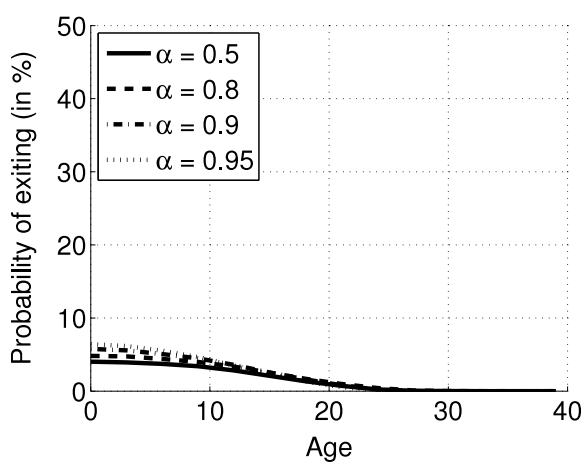

(a) DB pension scheme $(\omega=0)$.

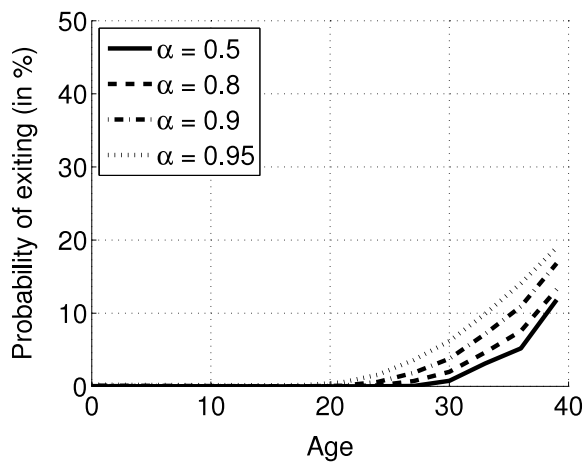

(c) Hybrid pension scheme $(\omega=0.5)$.

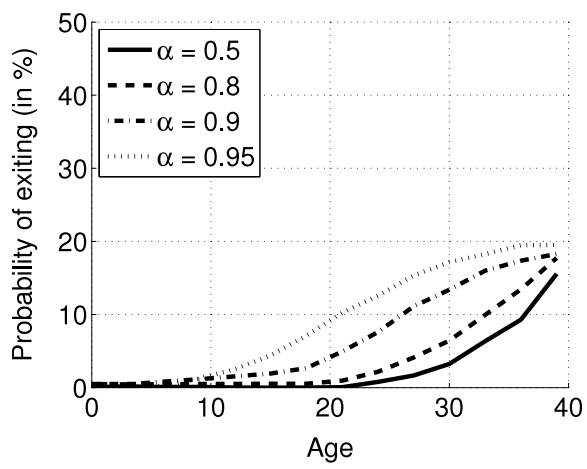

(e) Collective DC pension scheme $(\omega=1)$.

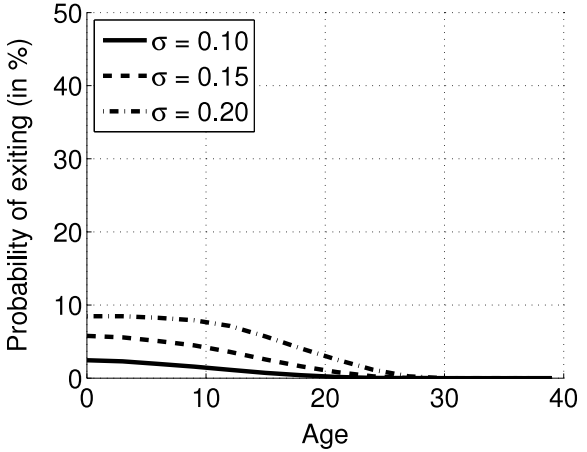

(b) DB pension scheme $(\omega=0)$.

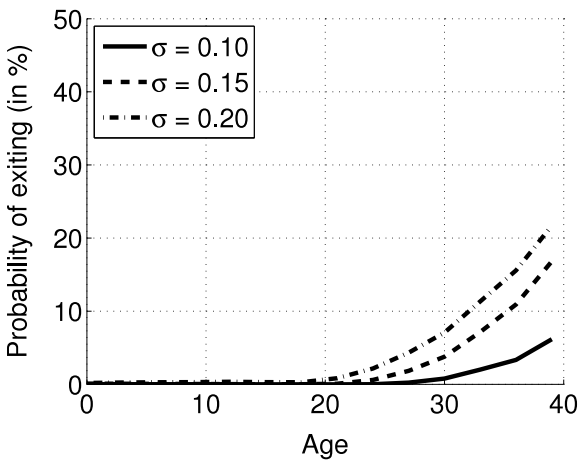

(d) Hybrid pension scheme $(\omega=0.5)$.

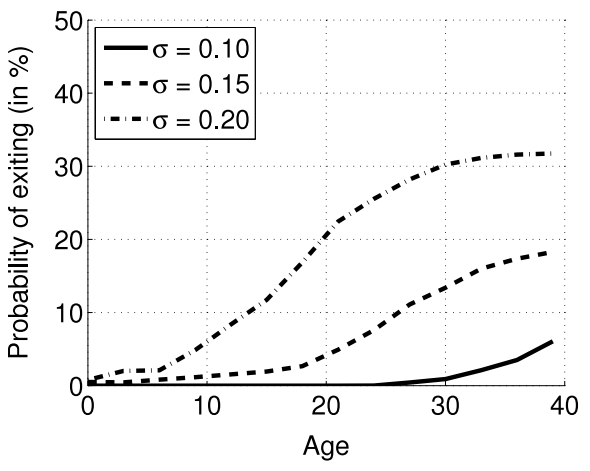

(f) Collective DC pension scheme $(\omega=1)$.

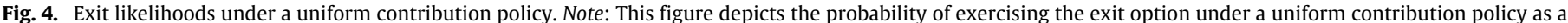
function of age for different values of the hybridity parameter $(\omega)$, the smoothing parameter $(\alpha)$ and investment risk $(\sigma)$.

Table 5

Likelihood that no cohort exits.

\begin{tabular}{|c|c|c|c|c|c|c|c|c|c|c|}
\hline & \multicolumn{4}{|c|}{$\omega=0(\mathrm{DB})$} & \multicolumn{3}{|c|}{$\omega=0.5$ (hybrid) } & \multicolumn{3}{|c|}{$\omega=1(\mathrm{CDC})$} \\
\hline & $\zeta$ & 0 & 0.5 & 1 & 0 & 0.5 & 1 & 0 & 0.5 & 1 \\
\hline \multirow{4}{*}{$\sigma=0.10$} & $\alpha=0.5$ & 97.5 & 98.0 & 97.8 & 44.0 & 44.0 & 43.9 & 27.0 & 27.0 & 27.0 \\
\hline & $\alpha=0.8$ & 97.6 & 98.1 & 98.3 & 44.5 & 44.5 & 44.5 & 24.7 & 24.7 & 24.5 \\
\hline & $\alpha=0.9$ & 97.6 & 98.2 & 98.5 & 43.7 & 43.5 & 43.4 & 20.6 & 20.4 & 20.3 \\
\hline & $\alpha=0.95$ & 97.8 & 98.5 & 98.8 & 40.0 & 40.0 & 39.7 & 14.4 & 14.3 & 14.2 \\
\hline \multirow{4}{*}{$\sigma=0.15$} & $\alpha=0.5$ & 96.0 & 96.9 & 95.2 & 54.8 & 54.8 & 54.7 & 40.5 & 40.3 & 40.0 \\
\hline & $\alpha=0.8$ & 95.2 & 96.3 & 95.7 & 54.8 & 54.7 & 54.4 & 35.4 & 34.3 & 33.5 \\
\hline & $\alpha=0.9$ & 94.2 & 95.5 & 95.5 & 53.9 & 53.5 & 52.1 & 25.1 & 24.8 & 24.4 \\
\hline & $\alpha=0.95$ & 93.6 & 94.8 & 95.3 & 51.3 & 49.4 & 46.7 & 22.7 & 22.3 & 21.9 \\
\hline \multirow{4}{*}{$\sigma=0.20$} & $\alpha=0.5$ & 95.8 & 95.8 & 93.7 & 56.3 & 56.0 & 55.5 & 22.3 & 21.6 & 21.0 \\
\hline & $\alpha=0.8$ & 93.5 & 94.1 & 92.9 & 54.8 & 54.3 & 53.2 & 15.5 & 15.0 & 15.0 \\
\hline & $\alpha=0.9$ & 91.5 & 92.1 & 91.5 & 53.2 & 51.5 & 49.6 & 16.8 & 16.6 & 16.6 \\
\hline & $\alpha=0.95$ & 88.5 & 89.6 & 89.6 & 51.1 & 48.3 & 45.3 & 16.0 & 16.0 & 16.1 \\
\hline
\end{tabular}

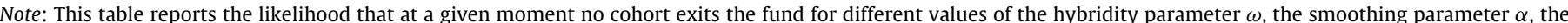

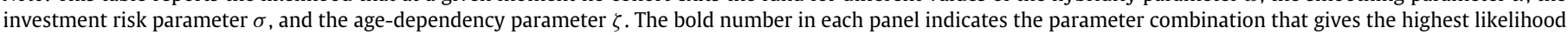
of no cohort exiting. 


\section{Conclusion}

Popular resistance against mandatory participation in collective pension schemes seems to be increasing, a development that has been fuelled by deteriorating pension funding ratios as a result of the recent economic and financial crisis and rising life expectancy, increased demand for freedom of choice and enhanced labour market mobility. This paper has explored the implications of giving pension fund participants the option to exit. We have considered a $\mathrm{DB}, \mathrm{a} \mathrm{CDC}$ and a hybrid pension scheme.

Our main findings are the following. First, participants are more inclined to continue to participate if the period over which the exit option can be exercised is longer. Hence, the value of the American exit option is highest for the youngest workers, which encourages them to participate in the pension fund. Second, the young working cohorts are most likely to exit under a DB pension scheme, while the older working cohorts are typically most likely to exit under the CDC pension scheme. Finally, we obtain several insights about the sustainability of the pension scheme, as measured by the likelihood that no cohort exits the scheme. Only when investment risk is low and recovery mainly relies on contributions, the likelihood that any specific cohort wants to exit falls when the recovery period is lengthened. However, with larger investment risk or when recovery mainly relies on indexation policy, shortening the smoothing period increases sustainability. Furthermore, under the uniform contribution policy the elderly workers are subsidized by young workers. At the same time the indexation policy increases the likelihood that the elderly cohorts exercise the option to exit, especially under a CDC scheme. Hence, a uniform contribution policy may help to enhance the sustainability of the fund.

Each cohort's exit option is implicitly paid for by the other participating cohorts. We leave the balance between the value of contributions and the value of benefits, both on an overall basis and on a cohort-by-cohort basis, for future research. The analysis in this paper can be extended into several other directions. One extension would be to consider more "refined" options, such as a partial withdrawal of accumulated assets from a pension fund or the possibility to withdraw resources only at the cost of a fine. The latter is quite common in the US. A second extension would be to include additional sources of risk into the model, such as demographic, interest rate and wage risks. Using the LSMC approach this may not be too complicated. However, not all of these risks are hedgeable, which contradicts the complete market assumption, hence rendering the risk-neutral pricing approach no longer applicable.

\section{Appendix A. Supplementary data}

Supplementary material related to this article can be found online at http://dx.doi.org/10.1016/j.insmatheco.2017.03.007.

\section{References}

Avdis, E., Wachter, J.A., 2016. Maximum likelihood estimation of the equity premium. Research Paper 57, Wharton School.
Ball, L., Mankiw, N.G., 2007. Intergenerational risk sharing in the spirit of Arrow, Debreu and Rawls, with applications to social security design. J. Polit. Econ. 115 (4), 523-547

Beetsma, R.M.W.J., Romp, W.E., 2013. Participation constraints in pension systems. Discussion Paper 09/2013-030, Netspar.

Beetsma, R.M.W.J., Romp, W.E., Vos, S.J., 2012. Voluntary participation and intergenerational risk sharing in a funded pension system. Eur. Econ. Rev. 56, $1310-1324$

Bernard, C., Lemieux, C., 2008. Fast simulation of equity-linked life insurance contracts with a surrender option. In: Winter Simulation Conference.

Bommel, J.v., 2007. Intergenerational risk sharing and bank raids. Working paper University of Oxford.

Bovenberg, A., Koijen, R., Nijman, T., Teulings, C., 2007. Saving and investment over the life cycle and the role of collective pension funds. De Econom. 155 (4), 347-415.

Boyer, M., Stentoft, L., 2013. If we can simulate it, we can insure it: An application to longevity risk management. Insurance Math. Econom. 52, 35-45.

Broeders, D., Chen, D., Minderhoud, P., Schudel, W., 2016. Pension funds' herding. Working Paper 503, DNB.

Cathcart, M., Morrison, S., 2009. Variable annuity economic capital: the leastsquares Monte Carlo approach. Life. Pension. 44-48.

Chen, D.H.J., 2015. Voluntary participation in a defined benefit pension scheme: An option pricing approach. Discussion Paper 11/2015-042, Netspar, Tilburg.

Chen, D.H.J., Beetsma, R.M.W.J., 2015. Mandatory participation in occupational pension schemes in the Netherlands and other countries. An update. Discussion Paper 10/2015-032, Netspar.

Chen, D.H.J., Beetsma, R.M.W.J., Ponds, E.H.M., Romp, W.E., 2016. Intergenerational risk-sharing through funded pensions and public debt. J. Pension Econ. Finance 15 (2), 127-159.

Chen, D.H.J., Romp, W., 2016. Modelling Pension fund Regulation and Stability. Mimeo, University of Amsterdam.

Cui, J., De Jong, F.C.J.M., Ponds, E.H.M., 2011. Intergenerational risk sharing within funded pension schemes. J. Pension Econ. Finance 10 (1), 1-29.

Delbaen, F., Schachermayer, W., 1994. A general version of the fundamental theorem of asset pricing. Math. Ann. 300 (1), 463-520.

DNB (2015). Herstelplan pensioenfondsen. www.toezicht.dnb.nl.

Dufresne, D., 1989. Stability of pension systems when rates of return are random. Insurance Math. Econom. 8 (1), 71-76.

Gollier, C., 2008. Intergenerational risk-sharing and risk-taking of a pension fund. J. Public Econ. 92 (5-6), 1463-1485.

Gordon, R., Varian, H., 1988. Intergenerational risk sharing. J. Public Econ. 37 $185-202$.

Hassler, J., Lindbeck, A., 1997. Intergenerational risk sharing, stability and optimality of alternative pension systems. Working Paper 493, IUI.

Hemert, O.v., 2005. Optimal intergenerational risk sharing. Discussion paper: UBS Pensions Series, 037 (541).

Kleinow, T., Schumacher, J., 2016. Financial fairness and conditional indexation. Scand. Actuar. J. 1-19.

Longstaff, F., Schwartz, E., 2001. Valuing American options by simulation: A simple least-squares approach. Rev. Financ. Stud. 14 (1), 113-147.

Madrian, B., Shea, D., 2001. The power of suggestion: Inertia in 401(k) participation and savings behavior. Quart. J. Econ. 116 (4).

Molenaar, R., Peijnenburg, J., Ponds, E., 2011. Should I stay or should I go? break even funding ratios for DB pension plan participants. Discussion Paper 04/2011-027, Netspar.

OECD, 2001. Private Pensions Series OECD 2000 Private Pensions Conference. In: Private Pensions Series, OECD Publishing.

OECD, 2013. Pensions at a Glance 2013: OECD and G20 Indicators. OECD, Paris.

Pelsser, A., Cao, J., den Iseger, P., 2007. Pricing hybrid options by an efficient Monte Carlo approach. Discussion Paper 12/2007-019, Netspar.

Ponds, E.H.M., Severinson, C., Yermo, J., 2011. Funding in public sector pension plans - international evidence. Working Paper w17082, NBER.

Shiller, R., 1999. Social security and institutions for intergenerational, intragenerational and international risk-sharing. In: Carnegie-Rochester Conf. Ser. Public Policy, Vol. 50, pp. 165-204.

Siegmann, A., 2011. Minimum funding ratios for defined-benefit pension funds. J. Pension Econ. Finance 10 (3), 417-434.

Westerhout, E., 2011. Intergenerational risk sharing in time-consistent pension schemes. Discussion Paper 03/2011-028, Netspar.

Westerhout, E., Bonenkamp, J., Broer, P., 2014. Collective versus individual pension schemes: a welfare-theoretical perspective. Discussion Paper 10/2014-045, Netspar. 